\title{
RNA Seq Analysis Reveal Differential Expression of Genes Associated With Metabolic Reprogramming, Defense and Signaling in Two Contrasting Indigenous Aromatic Rice Cultivars Differing in Redox Regulatory Properties Under Drought Stress
}

Nivedita Dey

University of Burdwan

Soumen Bhattacharjee ( $\nabla$ soumen1995@yahoo.com )

University of Burdwan

Research Article

Keywords: Aromatic Rice, Drought tolerance, Redox regulation, RNA-seq, Transcriptome.

Posted Date: January 19th, 2021

DOI: https://doi.org/10.21203/rs.3.rs-147276/v1

License: (c) (i) This work is licensed under a Creative Commons Attribution 4.0 International License.

Read Full License 
Nivedita Dey and Soumen Bhattacharjee*

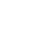
reprogramming, defense and signaling in two contrasting indigenous aromatic rice cultivars differing in redox regulatory properties under drought stress

\author{
Nivedita Dey and Soumen Bhattacharjee*
}

(1)

\title{
7
}

Plant Physiology and Biochemistry Research Laboratory, UGC Centre for Advanced Study, Department of Botany, The University of Burdwan, Burdwan, 713104, West Bengal, India 10 E-mail: soumen1995@yahoo.com / sbhattacharjee@bot.buruniv.ac.in

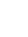


Abstract

\section{Background}

Though there are at present seventy indigenous aromatic rice cultivars being cultivated in West Bengal, India, the information regarding their genetic regulation of drought tolerance are scanty. Previous work from this laboratory has screened indigenous aromatic rice cultivars Badshabhog and Jamainadu as drought tolerant redox competent and drought susceptible redox incompetent germplasms respectivelybased on redox metabolomic investigation. In this backdrop, the present work comprehended to compare two indigenous aromatic rice cultivars for unfolding genetic regulation of drought stress.

\section{Results}

The result of comparative transcriptomic study through RNA-seq analysis in general revealed significant cultivar specific expression of genes under post-imbibitional dehydration stress as well as genes that are expressed in both the experimental cultivars (Oryza sativa L., cultivars Badshabhog and Jamainadu) with differential transcript abundance. 3482 and 3866 genes were found to be significantly down-regulated and up-regulated respectively when we compared between post-imbibitional dehydration stress-raised indigenous aromatic rice cultivars Badshabhog and Jamainadu. Transcripts selected for heatmap generation with proper annotation revealed 50 genes that are significantly expressed genes which are mainly involved in redox functions, signaling, membrane trafficking, replication and protein synthesis etc. On the contrary, genes which got highly expressed in Badshabhog found to be mainly concerned with carbondioxide concentrating mechanism (NADH-dependent malic enzyme), peroxysomal biogenesis, protein modification, protein synthesis, mitochondrial electron transport chain functioning, inercellular protein transport, histone demethylation 
associated with developmental process, regulation of apoptosis etc. Further Badshabhog exhibited greater GO (gene ontology) distribution so far as signaling, antioxidant functioning, biological and metabolic regulation, transcriptional and translational regulation etc. with significantly higher percentage of antioxidant genes. KEGG (kyoto encyclopedia of genes and genomes) pathway analysis showed several signal transduction pathways (abscisic acid, brassinosteroid, salicylic acid, jasmonic acid and ethylene) being influenced by drought stress.

\section{Conclusion}

The overall result of comparative transcriptomic investigation suggests that indigenous aromatic rice cultivars Badshabhog and Jamainadu explored varying strategies to deal with post-imbibitional dehydration stress. The cultivar Badshabhog exhibited a significantly greater molecular reprogramming presumably more through up-regulation of metabolic and energy demanding processes along with implementing better signaling strategies, antioxidative defense mechanism, DNA repair and transcriptional regulation vis-a-vis the cultivar Jamainadu.

Key words: Aromatic Rice, Drought tolerance, Redox regulation, RNA-seq, Transcriptome.

\section{Background}

Last few decades witnessed significant demand of aromatic rice internationally, due to their kernel quality and aroma [1]. Since the production of aromatic rice is largely threatened by environmental challenges, several comities across the globe put their effort for improving the existing aromatic rice cultivars based on genotype-environment interaction studies [2]. The overall observation revealed inverse relationship between yield and aroma quality, productivity under stress [3]. So, the target of achieving superior genotypes through selection 
of phenotypes of multiple complex traits is difficult due to varied genotype-environment interaction, genetic drag and inferior heritability [4]. Therefore, present time demands improvement of aromatic rice through the comprehensive study covering well annotated accession wise transcriptomic investigation under fluctuating environmental conditions $v i s-a-$ vis their standard metabolic and physiological phenotypes. So, comprehensive study exhibiting complexity of transcriptional regulation in diverse genotypes under prominent stress condition like drought is essential to augment corresponding breeding program. Since the high throughput that now makes it possible to generate cultivar specific transcriptome data, improvement of aromatic rice exploring RNA-seq analysis is one of the best options to study differential gene expression ability to combat stress in diverse genotypes of available aromatic rice cultivars [5]. Further screening is necessary for successful breeding program. In West Bengal, India, though approximately 70 indigenous aromatic rice cultivars (IARCs) are in practice, but their improvement through screening the best genotypes for breeding program using high throughput technologies are lacking [6].

Our previous study was undertaken to screen some drought tolerant IARCs of West Bengal, India based on their redox-regulatory attributes at metabolic interface [7, 8]. In this regard, the selection of the redox-metabolic and transcriptomic data for judicious screening of the germplasms of some IARCs of West Bengal for their drought tolerant attributes found to be extremely significant, though not always decisive in plant stress biology research [9-12]. Further, the work will also help us to identify and ascertain whether, the redox regulated traits or standardized redox biomarkers can be targeted by plant breeders for selection or genetic manipulation for improving the ability of the aromatic rice cultivars to grow under drought stress. 
One of the important approaches for understanding molecular insight or genetic regulatory mechanism into the extremely complicated regulatory signaling network including the redox signaling under abiotic stress involves comparative transcriptomic analysis in model plants. Both in Arabidopsis and rice, availability of complete reference genome enable us for sequencing their transcripts. Several workers in recent time, exploring transcriptome analysis, have revealed some important signaling and regulatory episodes under drought stress in both Arabidopsis and rice. For example, comparative transcriptomic investigation with RNA-seq analysis, in Arabidopsis has revealed the roles of some important transcription factors like WRKY70, WRKY46 etc. in up-regulating brassinosteroid mediated gene expression under drought stress [13]. Other workers [14] through their RNA sequence study also deciphered the roles of different hormonal signaling pathways [abscisic acid (ABA), jasmonic acid (JA), salicylic acid (SA), indole-3-acetic acid (IAA), gibberellic acid (GA) etc.] controlling metabolism during moderate drought stress of Arabidopsis. Xiong et al (2018) through their RNA sequencing and candidate gene analysis indicated the role of redox signaling under drought stress in rice [15]. Wang et al (2018) unfolded regulatory pathway involving ATBG1 and SYPCYP707A1/3 under drought stress in Arabidopsis [16]. Very recently other workers initiated some work towards understanding regulatory mechanisms associated with different magnitude of drought stress in rice through RNA-seq analysis. Bang et al (2019) characterized drought induced genes like DHHC4, AA4-type ATPases, CASPL5B1, modulin proteins etc. that regulate stomatal conductance, lignin deposition as contrivances of drought tolerance in rice [17]. Other important transcription factors, like NAC that exhibits upregulation under drought and regulate various redox events necessary for drought tolerance is also identified in rice by transcriptome analysis [18]. 
112 All these transcriptomic studies made so far in recent times exhibited significant implication

113 of the roles of specific genes and redox-regulatory genes in particular in drought stress

114 tolerance. Here, in this study, we made an attempt with comparative analysis of changes in

115 steady state level of transcript abundance through RNA sequencing of the redox competent

116 and redox incompetent experimental IARCs identified through investigation of redox biology

117 and physiological phenotyping of PIDS-raised seedlings and integrating them with redox

118 metabolic and physiological phenotypes. In fact, this system biology approach of

119 comprehensive physiological, metabolic and molecular regulatory mechanism regulating life

120 processes like germination under drought might help us to identify the reliable traits and

121 candidate genes for further breeding and transgenic experiments.

122 In this context, the present investigation of RNA-seq based comparative transcriptomic 123 analysis was undertaken for two IARCs (cultivars Badshabhog and Jamainadu) previously screened on the basis of their redox-regulatory attributes under drought stress. Exploring the roles of differentially expressed genes under drought stress in two contrasting IARCs might help us to unravel the metabolic pathways and signaling molecules that are associated with drought tolerance. Further, the work will also help to understand the transcriptional regulation of oxidative stress under drought for two contrasting genotypes of IARCs with distinct redoxregulatory properties at metabolic interface.

130 Results

Polyethylene glycol (PEG) induced post-imbibitional dehydration stress (PIDS) 
Previous experiments from this laboratory revealed significant differences in redox regulatory properties (modulation of ROS-antioxidant interaction status and sensitive metabolic redox biomarkers) between drought stress-raised IARCs Jamainadu and Badshabhog. When compared between these two experimental land races of aromatic rice, commonly cultivated in West Bengal, a clear difference in redox regulatory mechanisms have been revealed. Estimation of the components of the Halliwell-Asada pathway (both the redox metabolic turnover dynamics of ascorbate and glutathione and the activities of ascorbate peroxidase, dehydroascorbate reductase and glutathione reductase) revealed significant differences in processing of hydrogen peroxide $\left(\mathrm{H}_{2} \mathrm{O}_{2}\right)$ between the experimental IARCs. Badshabhog exhibited better regulation of the pathway through enhanced turnover dynamics of redox components (ascorbate and glutathione) of the pathway through maintenance or up-regulation of the enzymes involved under drought (Fig 1).

[Insert Fig 1 here]

Comparatively better $\mathrm{H}_{2} \mathrm{O}_{2}$ processing ability in the cultivar Badshabhog as compared to the cultivar Jamainadu under identical condition of post-imbibitional dehydration stress (PIDS) through maintenance of ascorbate-glutathione cycle can be corroborated from the studies of in situ localization of $\mathrm{H}_{2} \mathrm{O}_{2}$ (through laser confocal microscopy; Fig 2A and Fig 2B and TMB/ 3,3',5,5'- tetramethylbenzidine staining; Fig 2C and Fig 2D). Nitroblue tetrazolium (NBT) staining for localizing superoxide (precursor of $\mathrm{H}_{2} \mathrm{O}_{2}$ ) also revealed the same trend of result (Fig 2E and Fig 2F). 
159 Further, standardization of sensitive redox biomarkers of oxidative stress of germinating seeds of experimental IARCs grown under drought stress revealed significant changes of all the parameters [superoxide, hydrogen peroxide, DCFDA (2', 7'-dichlorofluorescindiacetate) oxidation, DPPH (2, 2'-diphenyl-1-pycryl hydrazyl) radical scavenging properties, activity of lipoxygenase and accumulation of membrane lipid and protein oxidation products (hydroperoxide, conjugated diene, thiobarbituric acid reactive substances and free carbonyl content)] under PIDS (Fig 3). However, when compared between these two, the PIDS-raised seedlings of cultivar Badshabhog in general exhibited significantly lesser magnitude of oxidative deterioration under PIDS as compared to Jamainadu (Fig 3). There was significant level of regulation of accumulation of total and individual ROS (DCFDA oxidation, superoxide and hydrogen peroxide accumulation) in the PIDS-raised seedlings of cultivar Badshabhog through down regulation of lipoxygenase activity and comparatively better radical scavenging property exhibited significant reduction of oxidative deterioration of membrane protein (free carbonyl content) and lipid (TBARS, hydroperoxide and conjugated diene) (Fig 3).

177 In fact, the extent of lipid peroxidation and protein oxidation, the two sensitive redox biomarkers of drought stress, showed significant differences between PIDS-raised IARCs, 
179 Badshabhog and Jamainadu. There is in general, 414.99\%, 110.71\%, 508.04\%, $174.05 \%$

180

181

182

183

184 more accumulations of hydroperoxide, TBARS, conjugated diene and free carbonyl content in the PIDS-raised seedlings of redox incompetent cultivar Jamainadu vis-a-vis the redox competent IARC Badshabhog.

The physiological phenotype assessed in terms of germination and early growth performences also strongly vouch the redox-regulatory properties of the experimental IARCs under drought. All the germination and early growth performance parameters $\left(\mathrm{T}_{50}\right.$ value, vigor index, relative germination performance, relative growth index, relative water content, co-efficient of velocity of germination, germination rate index, mean germination time and mean daily germination) strongly vouch better germination performance for the cultivar Badshabhog vis-a-vis the cultivar Jamainadu grown under the same magnitude of PEG-6000 madiated PIDS (Fig 4).

[Insert Fig 4 here]

Comparative Transcrpitomic investigation (RNA-seq analysis) of post-imbibitional dehydration stress (PIDS)-raised redox competent and incompetent IARCs (Badshabhog and Jamainadu) using Illumina platform and their functional annotation

To explore the molecular mechanism and genetic regulation of germination influenced by post-imbibitional dehydration stress (PIDS), RNA-seq analysis of the germinating seedlings of most tolerant and susceptible indigenous aromatic rice cultivars (IARCs) were conducted to generate the global transcriptome profiles. We compared the transcriptome profiles of 
PIDS-raised seedlings of the IARCs Jamainadu and Badshabhog (the most drought sensitive

202

203

204 and resistant genotypes respectively, as screened through redox metabolic and physiological investigation) (Fig 5 and Table 1). A total number of 4 libraries were constructed and analysed for each sample (approximately 18-20 million of total reads generated for each sample) (Fig 6, Fig 7 and Table 2) and mapped to rice genome (http://plants.ensembl.org/Oryza_indica/info/index) using HISAT2. Subsequently, the map files were processed via feature counts. The unity mapped reads for each replication total around 18-20 million (Table 5) and there were 16-18 million total mapped reads for PIDSraised IARCs, Jamainadu and Badshabhog respectively. Further, these were processed using features count for the determination of normalize expression level as the fragments of each transcript with per kilo base of transcript length per million mapped reads.

Total RNA was subjected to pair-end library preparation with Illumina TruSeq Stranded mRNA Library Preparation Kit. The mean sizes of the libraries are 292bp and 300bp respectively for samples PIDS (-1.619 MPa)-raised seedlings of IARC, Jamainadu (SBND1) and PIDS (-1.619 MPa)-raised seedlings of IARC, Badshabhog (SBND2). The libraries were sequenced using 2x150bp PE chemistry on Illumina platform for generating 3 GB data per sample.

\section{[Insert Fig 5 here]}


Table 1: Quantification using Qubit® 2.0 Fluorometer

\begin{tabular}{|c|c|c|c|}
\hline SAMPLES & $\begin{array}{c}\text { Concentration } \\
(\mathrm{ng} / \mu \mathrm{l})\end{array}$ & Yield (ng) & Remarks \\
\hline JPIDS (-1.619 MPa)-raised seedlings of IARCs] & 410 & 11.4 & QC Pass \\
\hline Bamainadu & 520 & 14.5 & $\begin{array}{c}\text { Partially } \\
\text { degraded }\end{array}$ \\
\hline
\end{tabular}

The next generation sequencing for all 2 samples [PIDS (-1.619 MPa)-raised seedlings of IARCs, Jamainadu and Badshabhog] were performed using Illumina Platform. The data statistics of High quality data is provided in the below table.

Table 2: HQ data statistics

\begin{tabular}{|c|c|c|c|c|}
\hline $\begin{array}{c}\text { Samples } \\
\text { [PIDS (-1.619 MPa)-raised } \\
\text { seedlings of IARCs] }\end{array}$ & Total reads & Total Reads & $\begin{array}{c}\text { Total no of bases } \\
(\boldsymbol{R} 1+\boldsymbol{R} 2)\end{array}$ & $\begin{array}{c}\text { Data } \\
(\boldsymbol{G b})\end{array}$ \\
\hline Jamainadu & $9,413,217$ & $18,826,434$ & $2,715,971,890$ & 2.7 \\
\hline Badshabhog & $10,330,002$ & $20,660,004$ & $2,990,081,749$ & 3 \\
\hline
\end{tabular}




\section{Bioinformatics workflow}

236 Reference guided transcript assembly was performed for all the samples, first by mapping 237 HQ reads on reference genome using hisat2 (v 2.2.1) and then performing transcript assembly 238 by StringTie (v 2.1.4). A consensus set of transcripts was obtained using SringTie merge 239 function which merges together all the gene structures found in any of the samples. 240 Transcript abundance was then estimated using merged transcript consensus again using 241 StringTie and read counts thus obtained for each transcript were taken as input for differential expression analysis using edgeR package. Gene ontology (GO) and pathway analysis of the differentially expressed transcripts were performed using UniprotKB and KEGG-KAAS (Kyoto encyclopedia of genes and genomes-KEGG automatic annotation server) server respectively.

\section{Reference genome information}

The reference genome of Oryza sativa Indica Group and its corresponding GTF file was downloaded from ensembl database (http://plants.ensembl.org/Oryza_indica/info/index)

(Table 3). The genome of Oryza sativa is of $\sim 374 \mathrm{Mb}$.

Table 3: Reference genome statistics

251

252

253

254

\begin{tabular}{|c|c|}
\hline Description & Stats \\
\hline \# Chromosomes & 12 \\
\hline Total genome length (bp) & $374,545,499$ \\
\hline Mean sequence size (bp) & $31,212,124$ \\
\hline Max sequence size (bp) & $47,283,185$ \\
\hline Min sequence size (bp) & $21,757,032$ \\
\hline
\end{tabular}


The reference GTF (gene transfer format) file contains genome annotation. It includes

257 information (locus and description) regarding genes and proteins. There are a total of 38,676 genes as per the GTF file of ensembl's Oryza sativa reference genome (Table 4).

Table 4: Detail Information of GTF file of ensembl's Oryza sativa L. Indica genome

\begin{tabular}{|c|c|}
\hline Genome elements & \# sequences \\
\hline gene & 38,676 \\
\hline CDS & 165,685 \\
\hline exon & 166,492 \\
\hline Start codon & 37,878 \\
\hline Stop codon & 37,878 \\
\hline Transcript & 38,676 \\
\hline
\end{tabular}

\section{Mapping to reference genome}

262

263

264

265

266

267

268

269

270

271

Before mapping, indexing of the reference genome was carried out using hisat-build (HISAT2 specific indexer program). Then the input reads, in FASTQ format, were given to HISAT2 aligner along with the reference genome index for alignment. Thus analysis begins by mapping HQ reads against the Oryza sativa Indica, reference genome using HISAT2 to create alignment in SAM/BAM format for each sample. This is to identify the positions from where the reads originated. This mapping information allows us to collect subsets of the reads corresponding to each gene, and then to assemble and quantify transcripts represented by those reads. The mapping statistics are provided in the table 5 


\begin{tabular}{|c|c|c|c|}
\hline $\begin{array}{c}\text { Samples } \\
\text { [PIDS (-1.619 MPa)-raised } \\
\text { seedlings of IARCs] }\end{array}$ & $\begin{array}{c}\text { Total Reads } \\
(\boldsymbol{R} 1+\text { R2) }\end{array}$ & No. of mapped reads & \% of mapped reads \\
\hline Jamainadu & $18,826,434$ & $16,890,240$ & $89.72 \%$ \\
\hline Badshabhog & $20,660,004$ & $18,436,279$ & $89.24 \%$ \\
\hline
\end{tabular}

\section{Transcript assembly}

275 StringTie assembles transcripts from RNA-seq reads that have been aligned to the genome,

276 first grouping the reads into distinct gene loci and then assembling each locus into as many

277 isoforms as are needed to explain the data. Following this, StringTie simultaneously

278 assembles and quantify the final transcripts by using network flow algorithm and starting

279 from most highly abundant transcripts. The reference genome GFF (general feature format)

280 annotation files, containing exon structures of "known" genes, are then used to annotate the

281 assembled transcripts and quantify the expression of known genes as well derive clues if a

282 novel transcript has been found in the sample.

283 After assembling each sample, the full set of assemblies is passed to StringTie's merge 284 function, which merges together all the gene structures found in any of the samples. This step 285 is required because transcripts in some of the samples might only be partially covered by reads, and as a consequence only partial versions of them will be assembled in the initial StringTie run. The merge step creates a set of transcripts that is consistent across all samples, so that the transcripts can be compared through some important steps. The statistics of merged transcripts and individual transcript assembly is provided in the table 6 . 
Table 6: Statistics of transcript assembly

\begin{tabular}{|c|c|}
\hline Sample Name & \# Assembled Transcripts \\
\hline Merged GTF & 55,886 \\
\hline $\begin{array}{c}\text { PIDS (-1.619 MPa)-raised seedlings of IARC, } \\
\text { Jamainadu }\end{array}$ & 37,051 \\
\hline $\begin{array}{c}\text { PIDS (-1.619 MPa)-raised seedlings of IARC, } \\
\text { Badshabhog }\end{array}$ & 37,972 \\
\hline
\end{tabular}

292

293 The output consists of assembled gene/transcript GTF file for all samples and another GTF

294 file resulting from the merge step are as described above.

\section{Comparison of assembled transcripts with reference transcripts}

296 For comparison of assembled transcripts with reference transcripts, Gffcompare utility was run taking the reference GTF and the string-tie merged GTF file. This produces an output file, which adds to each transcript a "class code" and the name of the transcript from the reference annotation file to check how the predicted transcripts relate to an annotation file. Meaning of each class code is depicted in figure 8. Potential novel isoform (Class code " $\mathrm{j} "$ ) that shares at least one splice junction with a reference transcript were extracted. A total of 7,739 novel isoforms with the class code " $\mathrm{j}$ " were identified. 
309 Abundances of the merged transcripts in all the 2 samples were estimated using StringTie. A python program (prepDE.py) was used to extract the read count information directly from the

311 files generated by StringTie.

312 For differential expression analysis, sample comparison was made as shown in table 7.

313 Table 7: Sample comparison for differential expression analysis

\begin{tabular}{|c|c|}
\hline Sample SBND1 & Sample SBND2 \\
\hline $\begin{array}{c}\text { PEG-6000 induced seedlings of IARC, } \\
\text { Jamainadu }\end{array}$ & $\begin{array}{c}\text { PEG-6000 induced seedlings of IARC, } \\
\text { Badshabhog }\end{array}$ \\
\hline
\end{tabular}

315 Differential gene expression (DGE) was inferred between sample groups by applying the R 316 package edgeR (v3.28.1). edgeR is a bioconductor package based on negative binomial 317 distribution method. The analysis provides tabular result and the description of each column 318 is provided in the table 8.

319 Table 8: Column description of DESeq output

\begin{tabular}{|c|c|}
\hline Column Name & Feature identifier \\
\hline CPM(control) & $\begin{array}{c}\text { Reads per million mapped reads or Counts per million mapped reads (CPM) } \\
\text { of Control sample }\end{array}$ \\
\hline CPM(Test) & $\begin{array}{c}\text { Reads per million mapped reads or Counts per million mapped reads (CPM) } \\
\text { of Treated sample }\end{array}$ \\
\hline $\log 2$ FoldChange & the logarithm (to basis 2) of the fold change(treated/control) \\
\hline logCPM & Log10 of CPM value \\
\hline pval & pvalue for the statistical significance of this change \\
\hline FDR & FDR adjusted pvalue (q-value) \\
\hline
\end{tabular}


323 The criterion used to identify up-regulated and down-regulated transcripts along with the

324 significance is provided in the table 9

325 Table 9: Criteria used to identify up-regulated and down-regulated genes and assigning the significance

\begin{tabular}{|c|c|}
\hline Condition & Status \\
\hline $\log 2 \mathrm{FC}>0$ & Up regulated \\
\hline $\log 2 \mathrm{FC}<0$ & Down regulated \\
\hline $\log 2 \mathrm{FC}>0$ and q-value $<0.05$ & Significantly up regulated \\
\hline $\log 2 \mathrm{FC}<0$ and q-value $<0.05$ & Significantly down regulated \\
\hline
\end{tabular}

328 Differential expression analysis statistics is provided in table 10.

Table 10: Differential gene expression statistics

\begin{tabular}{|c|c|c|c|c|c|}
\hline Combination & $\begin{array}{c}\text { Total } \\
\text { Differentially } \\
\text { expressed } \\
\text { gene }\end{array}$ & Down-regulated & Up-regulated & $\begin{array}{c}\text { Significant } \\
\text { Down- } \\
\text { regulated }\end{array}$ & $\begin{array}{c}\text { Significant } \\
\text { Up-regulated }\end{array}$ \\
\hline $\begin{array}{c}\text { PIDS-raised } \\
\text { seedlings } \\
\text { (-1.619 MPa) } \\
\text { of IARCs, } \\
\text { Jamainadu } \\
\text {-Vs- } \\
\text { Badshabhog }\end{array}$ & 32,988 & 16,177 & 16,811 & 3,482 & 3,866 \\
\hline
\end{tabular}


331 The Venn diagram representing number of genes expressed in both the seedlings of

332

333

334

335

336

337

338

339

340

341

342

343

344

345

346

347

348

349

\section{[Insert Fig 9 here]}

\section{Heat map for significantly expressed differential genes in combination}

List of transcripts were selected for heatmap generation based on following criteria

- Significantly expressed transcripts present in both the samples and highly regulated in terms of $\log 2$ FoldChange (top 50 transcripts).

- Transcripts must have proper annotations.

pheatmap package from $\mathrm{R}$ software was used for producing heatmap. The color coding ranges from red to blue where shades of red represent high transcripts expression and shades of blue represents low transcript expression (Fig 10).

\section{[Insert Fig 10 here]}


351 The plot visualizes the differences between measurements taken in two samples, by

352 transforming the data onto $\mathrm{M}$ (log ratio) and $\mathrm{A}$ (mean average) scales, then plotting these 353 values (Fig 11).

\section{[Insert Fig 11 here]}

\section{Volcano plot for significantly expressed differential genes in combination}

The "volcano plot" arranges expressed genes along dimensions of biological as well as statistical significance (Fig 12).

The Gene Ontology data provides controlled defined terms representing gene product properties. These cover three domains: Cellular Component, the parts of a cell or its extracellular environment; Molecular Function, the elemental activities of a gene product at the molecular level, such as binding or catalysis; and biological process, operations or sets of molecular events with a defined beginning and end, pertinent to the functioning of integrated living units: cells, tissues, organs, and organisms. For obtaining gene ontology for 
differentially expressed transcripts, they were first annotated against Uniprot database

Table 11: GO Distribution of Differential expression transcripts

\begin{tabular}{|c|c|c|c|c|}
\hline Combination & $\begin{array}{c}\text { \# Total } \\
\text { DEG }\end{array}$ & $\begin{array}{c}\text { Cellular } \\
\text { Component }\end{array}$ & $\begin{array}{c}\text { Biological } \\
\text { Process }\end{array}$ & $\begin{array}{c}\text { Molecular } \\
\text { Function }\end{array}$ \\
\hline $\begin{array}{c}\text { PIDS-raised (-1.619 MPa) seedlings of } \\
\text { Jamainadu -Vs- PIDS-raised (-1.619 MPa) } \\
\text { seedlings of Badshabhog }\end{array}$ & 32,988 & 20,942 & 19,412 & 19,909 \\
\hline
\end{tabular}

The comparative Gene ontology (GO) of both PIDS-raised experimental IARCs Badshabhog and Jamainadu considering 7348 DEGs [that includes genes expressed in both the land races as well as uniquely up-regulated genes (q-value <0.05)] are given in figure $14 \mathrm{~A}$ and $14 \mathrm{~B}$.

From this status of DEG, further, genes are taken which are uniquely up-regulated in either experimental IARCs Jamainadu or Badshabhog (i.e., present exclusively in both the experimental land races). Such exclusively up-regulated genes for Jamainadu and Badshabhog are 1741 and 2109 respectively (Fig 15A and 15B). 


\section{Pathway analysis}

Ortholog assignment and mapping of the differentially expressed transcripts to the biological 392 pathways were performed using KEGG automatic annotation server (KAAS). Differentially expressed transcripts were compared against the KEGG database using BLASTX with threshold bit-score value of 60 (default). Pathway analysis was performed using all differentially expressed transcripts. The mapped transcripts represented metabolic pathways of major biomolecules such as carbohydrates, lipids, nucleotides, amino acids, glycans, cofactors, vitamins, terpenoids, polyketides, etc. The mapped transcripts also represented the genes involved in metabolism, genetic information processing, and environmental information processing and cellular processes (Table 12 and Fig 16).

400

401

\section{[Insert Table 12 and Fig 16 here]}

402

Apart from plant hormone signal transduction KEGG pathways that have depicted with one gene entry or functional unit of the pathway, separate pathways for both the experimental land races raised from PIDS for uniquely up-regulated genes (1741 genes for Jamainadu -Vs2109 genes of Badshabhog) with q-value $<0.05$ is given in Table 13.

407 
409 Further, Kyoto encyclopedia of genes and genomes (KEGG) analysis to characterize and 410 identify enriched pathways contributed by drought responsive DGE in both the experimental 411 IARCs, it was revealed that apart from metabolism (the most significantly enriched 412 pathways), environmental information processing and genetic information processing 413 constitute the core DEGs in these pathways for the experimental IARCs, indicating the roles of signaling pathways and gene expression reprogramming and regulation in drought tolerance of both the experimental IARCs.

\section{Discussion}

417 The selection of physiological, metabolic and molecular markers for judicious screening of 418 germplasms of rice for their drought stress tolerance is extremely significant, though not always a decisive approach in agricultural research. The integration of 'omic' approaches, as in marker assisted selection along with important metabolic and biochemical data always ensures a system level information of the complex drought response necessary for tolerance $[10,19,20]$. In this aspect, the effectiveness of drought induced oxidative stress tolerance through redox regulation may be used as quality traits for standardizing biomarkers of drought stress tolerance [21-25]. In this background, the present work made an effort to assess and standardize some important redox metabolic and molecular parameters along with their physiological phenotyping for screening some IARCs commonly cultivated in West

427 Bengal, India. In this regard, the integration of redox metabolic and physiological data along 428 with genomic data of drought induced IARCs ensues a better understanding of complex redox-regulatory traits of plants in conferring drought tolerance. The present work, in this perspective, explores the redox biology of PIDS induced seedlings of two important IARCs 
mechanisms necessary for drought tolerance but may also be used as stress tolerance biomarkers for screening drought resistant germplasms of aromatic rice.

Two contrasting indigenous aromatic rice cultivars (drought sensitive Jamainadu and drought tolerant Badshabhog) screened on the basis of comparative redox biology and physiological phenotyping were further investigated for unfolding genetic regulation of drought stress based on comparative transcriptomics using RNA-seq. Through RNA-seq analysis and subsequent functional annotation of the data, I have identified differential expression of genes between PIDS-raised seedlings of IARCs Jamainadu and Badshabhog. In order to reduce the artifacts, several filtering parameters were employed during data analysis. Genome reference sequence had been utilized to unfold the best impact on the downstream analysis such as number and variety of DEGs.

When we compared the differential expression of genes between PIDS-raised seedlings of Jamainadu and Badshabhog, a total of 32988 genes found to be differentially expressed. Further, when I compared between these two, 16177 genes found to be down-regulated in Badshabhog as compared to 16811 up-regulated genes. However, when the significant downregulated and up-regulated genes were compared between PIDS-raised Jamainadu and Badshabhog, the number became 3482 and 3866 respectively. When the list of transcripts were selected for heatmap generation based on significantly expressed transcripts present in both the samples (highly regulated in terms of $\log 2$ fold change $(\log 2 \mathrm{FC})$ with proper annotations, 50 genes were highlighted which mainly include redox genes, GTPase activity protein, lysine specific demethylase, NADH-dehydrogenase, peroxisome biogenesis protein, GDSL-esterase/lipase transport protein ACC-61, ATP-dependent RNA helicase etc. So the genes commonly up-regulated in both the genotypes under water stress mainly involves redox 
functions, signaling, membrane trafficking, replication and protein synthesis and metabolic role.

The genes otherwise differentially expressed significantly (highly expressed genes) under PIDS in redox competent IARC Badshabhog as compared to redox incompetent IARC jamainadu includes NADH-dependent malic enzyme isoform (MSTRG2338.1), SUMO activating enzyme subunit 2 isoform XI (MSTRG.21850.1), 60S ribosomal protein (BGI Os GA 001808-TA), peroxysome biogenesis protein isoform XI (BGI 0SGAO28937TA), NADH dehydrogenase (Ubiquinone) 1 beta complex subunit (BG10SGA033496-TA), RAS related protein RABE1C (BG10SGA013829-TA), lysine specific demethylase SE14 like isoform (MSTRG.10912.2), stromal cell derived factor 2 like protein (MSTRG.23102.1) and hypothetical protein OSI_38644 ( BGI0SGA036042-TA), hypothetical protein Os1_12555, hypothetical protein 32602. The other genes which got significantly down-regulated in PIDSraised seedling of IARC Badshabhog in comparison to the cultivar Jamainadu (where these genes got significantly expressed) include eukaryotic translation initiation factor JA2polyubiquitin A, 60S ribosomal protein, hypothetical protein CR513_38538, FT interacting protein 1, GDSL esterase/ lipase LTL1. The genes which got highly expressed in Badshabhog are found to be mainly concerned with $\mathrm{CO}_{2}$ concentrating mechanism (NADH472 dependent $\mathrm{ME}$ ), peroxysomal biogenesis, protein modification, protein synthesis (60S 473 ribosomal protein), mitochondrial ETC functioning (NADH dehydro ubiquinone), intercellular protein transport (rabc1-RAS related protein), histone demethylation associated with developmental process (lysine specific demehylase), regulation of apoptosis (stromal cell related factor 2 like protein). So, deep dissection of significantly over-expressed protein

477 in redox-competent IARC Badshabhog revealed their better cellular and molecular activities 
along with metabolic regulation to cope up with drought stress, when compared to the IARC Jamainadu [26-30].

Other genes, though not expressed significantly but exhibited marginal up-regulation in the IARC Badshabhog as compared to Jamainadu includes redox genes [L-ascorbate oxidase/ peroxidase, monothiol glutaredoxin-S1, thioredoxin-like protein AAED1 (chloroplastic), thioredoxin-like protein CXXS1, NADH-dehydrogenase (ubiquinone)-1-beta subcomplex subunit 3-B, NADH-dehydrogenase subunit 6 and K, lipoxygenase 6 isoform-XI etc.], signal transduction related genes (dehydration-responsive element-binding protein 1I, auxin-related protein 1 isoform $\mathrm{X} 1$, auxin efflux career component 3a isoform $\mathrm{X} 1$, auxin response factor 16 isoform X1, auxin-responsive protein SAUR 19, SAUR36, SAUR77, ethylene-responsive transcription factor 5, ethylene-responsive transcription factor ERF177, $\mathrm{Ca}^{2+}$-dependent protein kinase12, 17, 4 isoformX1, calmodulin-binding protein $60 \mathrm{~B}$ isoform $\mathrm{X} 1$, MAP kinase14, MAP kinase kinase kinase 1, MAP kinase kinase kinase ANP1, serine/threonineprotein kinase OsK4, BSK2, D6PK etc.), transcription factor related genes (MybS1, NAI1, WRKYtranscription factor 32, bZIP transcription factor 16 isoform X2, bZIP transcription factor TRAB1, ethylene responsive transcription factor 5, transcription factor BHLH113, BHLH18, BHLH79 etc.), replication and protein synthesis related genes (40S ribosomal protein S11, S18, S24-1, S-9; 60S ribosomal protein L18a, L24, L26-1,L29-1, ATPdependent helicase BRM, ADP ribosylation factor 2, DNA-directed RNA polymerase I, DNA repair protein XRCC4 etc.) transporter related genes [ABC transporter B family member 28, 13, 37, 39, 41, 45, K-transporter1, $\mathrm{K}(+)$ efflux antiporter 4, amino acid permease BAT1, amino acid permease 3 and 4] and metabolic genes [ $\alpha$-amylase/trypsin inhibitor, anthocyanin reductase (2S)-flavan-3-ol-forming, probable chalcone-flavonone isomerase 3, ART1, 
chalcone-flavonone isomerase, cysteine synthase, cysteine protease, isoflavone 3'hydroxylase isoform $\mathrm{X} 1$, isochorismate synthase 1 etc.].

503 So, the comparison of transcript between PIDS-raised seedlings of Jamainadu and 504 Badshabhog suggests that there is a major difference in the number of genes expressed under identical condition of PIDS. Jamainadu, the drought susceptible IARC (screened on the basis of investigation of redox biology and physiological phenotyping), exhibited a moderate transcriptional response when exposed to water stress. While the drought tolerant IARC, Badshabhog (screened on the basis of investigation of redox biology and physiological phenotyping) showed the modest transcriptional expression. These findings potentially show that the cultivar Badshabhog is relatively transcriptionally stable under dehydration stress as compared to Jamainadu. This result is in concurrence with the previous result of Yang et al (2017) and Ereful et al (2020) [28, 30].

Functional annotations of transcript data involving gene ontology (GO) provide information on potential functions of genes as well. For obtaining gene ontology for differentially expressed transcripts, they were first annotated against uniprot database following mapping against uniprotKB. GO domain distribution showed that out of 32988 differentially expressed transcripts in PIDS-raised seedlings of Jamainadu and Badshabhog, 20942 belongs to cellular component, 19412 belongs to biological process, 19909 belongs to molecular function. So far as molecular function is concerned it was estimated through GO distribution of DEG that

520 almost $1 \%$ of differentially expressed genes in drought susceptible IARC Jamainadu and drought resistant IARC Badshabhog belongs to antioxidant activity. Other notable molecular function related to differentially expressed transcripts are transcriptional and translational regulatory activity, important cellular processes, biogenesis of important cellular component and carrier activity etc. The GO distribution for biological processes that showed the 
differential expression of transcripts between Jamainadu and Badshabhog mainly involves signaling, regulation of biological processes, metabolic processes, response to stress/stimuli, positive and negative regulation of metabolic processes etc. The percentage of genes involved in antioxidant functioning, cell signaling and regulation of biological processes also accounts

529 for more than $1 \%$ percentage of genes. So, the IARC, Badshabhog exhibited greater GO distribution so far as cell signaling antioxidant, biological and metabolic regulation, transcriptional and translational regulation etc. are concerned. Similar kind of results has been noticed by Toni et al (2017) [31] and Ereful et al (2020) [30]. So, the comparison of transcript between PIDS-raised seedlings of Jamainadu and Badshabhog suggests that there is a major difference in the number of genes expressed under identical condition of PIDS. Jamainadu, the drought susceptible IARC (screened on the basis of investigation of redox biology and physiological phenotyping), exhibited a moderate transcriptional response when exposed to water stress. While the drought tolerant IARC, Badshabhog (screened on the basis of investigation of redox biology and physiological phenotyping) showed the modest transcriptional expression. These findings potentially show that the cultivar Badshabhog is relatively transcriptionally stable under dehydration stress as compared to Jamainadu. This result is in concurrence with the previous result of Yang et al (2017) and Ereful et al (2020)

$542[28,30]$. The significantly higher percentage of antioxidative genes, differentially expressed in Badshabhog as compared to Jamainadu corroborate the fact that the IARC Badshabhog is capable of scavenging more reactive oxygen species and restore redox homeostasis under similar kind of PIDS. Moreover the greater transcript abundance associated with signaling, biological regulation and response to stimulus for the PIDS-raised Badshabhog as compared to Jamainadu also supports the better preparedness of the IARC, Badshabhog under PIDS through cell signaling and metabolic adjustment [30, 32]. 
549 Ortholog assignments and mapping of differentially expressed transcripts to the biological 550 pathways were performed using KEGG automatic annotation server (KAAS). Subsequently 551 the differentially expressed transcripts were compared against KEGG database, BLASTX 552 with threshold bit-score value. Here the map transcripts represented metabolic pathways of 553 major biomolecules as well as environmental regulation of those pathways and cell signaling.

554 The growth signaling KEGG pathways, that has been assigned to at least one gene entry or an 555 ortholog table entry that correspond to a gene that is part of the functional unit of the pathway showed several signal transduction pathway being influenced by drought stress. The most 557 important of which are abscisic acid, brassinosteroid, salicylic acid, jasmonic acid and ethylene. The role of these hormonal pathways in one way or another is influenced by the redox status of the cells. So, the differences in redox-regulatory properties under PIDS between the cultivars Jamainadu and Badshabhog seems to have differential impact on the transcript abundance of some of the genes associated with these signaling molecules. In fact, the biosynthesis of metabolites like phenylalanine, linoleic acid, brassinosteroid, cysteine, methionine and carotenoids seems to have profound impact on the metabolism and signaling of salicylic acid (SA), jasmonic acid (JA), brassinosteroid (BS), ethylene and abscisic acid (ABA) respectively. Badshabhog in general showed significant up-regulation of important genes of these metabolic pathways. ABA, JA, SA and ethelyne play key role in responding to environmental stresses [33]. Using KEGG pathway analysis, it was found that both the IARCs, Jamainadu and Badshabhog found to have impact on these hormonal pathways and signaling but when compared the tolerant IARC Badshabhog seems to have better response for drought tolerance. 


\section{Conclusion}

574 The overall result of comparative transcriptomic investigation suggests that IARCs

575 Badshabhog and Jamainadu explore varying strategies to deal with PIDS. The cultivar

576 Badshabhog exhibited a significantly greater molecular reprogramming presumably more

577 through up-regulation of metabolic and energy demanding processes along with

578 implementing better signaling strategies to deal with drought stress during early germination.

579 The defensive strategies as adopted through antioxidative defense mechanism, DNA repair

580 and transcriptional regulation are also seems to be the better adopted by IARC Badshabhog

581 vis-a-vis the cultivar Jamainadu. The signaling pathway including ABA, JA, SA, ethylene

582 and IAA which either individually are in association with redox cue were shown to be

583 significantly up-regulated in Badshabhog. The controlled redox-regulatory event that

584 generates conducible internal redox cue in PIDS-raised IARC Badshabhog might have augment hormonal signal transduction pathways, receptor activity and metabolic reprogramming associated with drought tolerance. Though both the experimental IARCs employ genetic regulation through overall metabolic processes, regulation of transcription, ion balance, programmed cell death etc. for survival, but the cultivar Badshabhog showed enhanced transcriptional regulation associated with peroxisomal and chloroplastic pathways, cell signaling, defensive processes under drought stress during early germination as compared to cultivar Jamainadu. These findings necessitates further dissection of this drought induced attributes in the screened drought tolerant IARC Badshabhog. So, the present study clearly revealed molecular basis of metabolic competence including redox-regulatory properties of

594 two contrasting IARCs under drought stress. The information generated from this 595 comparative transcriptome analysis along with their sensitive redox-metabolic data will definitely assist rice breeders in breeding program for augmenting the productivity of IARCs. 
Collection of experimental germplasms of indigenous aromatic rice cultivars (IARCs) and their maintenance in Crop Research and Seed Multiplication Farm (CRSMF), The University of Burdwan

Seeds of two experimental indigenous aromatic rice cultivars [IARCs Oryza sativa L., Cultivars Jamainadu and Badshabhog, commomnly cultivated in different areas of West Bengal)], were collected from Chinsurah Rice Research Station, Chinsurah, Government of West Bengal, India and the germplasms were multiplied and maintained at Crop Research and Seed Multiplication Farm (CRSMF), The University of Burdwan, Burdwan, West Bengal, India.

\section{Treatment of PEG-6000 to induce post-imbibitional dehydration stress (PIDS)}

608

609

610

611

612

613

614

Seeds of the two indigenous aromatic rice cultivars [IARCs (Oryza sativa L., Cultivars Jamainadu and Badshabhog)], selected as experimental material, have been collected from Chinsurah Rice Research Station, West Bengal, and later grown in CRSMF for three successive years. Seeds of the experimental cultivars grown at CRSMF, were washed with distilled water and were treated with $0.2 \% \mathrm{HgCl}_{2}$ for 5 minutes and then washed thrice with sterile distilled water. The surface sterilized seeds were imbibed in distilled water for 48 hours in darkness at $25^{\circ} \pm 2^{\circ} \mathrm{C}$ and thereafter, were sown on moist filter paper in petri plates and were placed in standardized conditions of thermostat-controlled seed germinator cum stability chamber, maintained at $25^{\circ} \pm 2^{\circ} \mathrm{C}$ temperature. For imposing post-imbibitional dehydration stress, water-imbibed seed lots of each cultivar were treated with $-1.619 \mathrm{MPa}$ PEG-6000 for 7 days, with intermittent change of treating solutions in petri plates. Dose of PEG-6000 for imposing PIDS were standardized based on initial pilot experiment. For 
untreated control set, water imbibed seeds were sown directly in petri plates on moist filter paper. All the seed lots were allowed to grow at $25^{\circ} \pm 2^{\circ} \mathrm{C}$ with 14 hour photo period (light intensity $270 \mu \mathrm{mol} \mathrm{m} \mathrm{m}^{-2}$ ) and $78 \pm 2 \%$ relative humidity. For all biochemical analysis 168 hours old seedlings raised from aforesaid conditions were used.

\section{Assessment of ROS-antioxidant interaction dynamics}

\section{Efficiency of Halliwell-Asada pathway}

Extraction and estimation of associated antioxidant enzymes (ascorbate peroxidase, dehydroascorbate reductase and glutathione reductase)

Ascorbate peroxidase (APOX, EC 1.11.1.11) activity was determined according to Nakano and Asada (1981) [34]. Homogenate was prepared by homogenizing the tissue (500 $\mathrm{mg}$ ) with $5 \mathrm{~mL}$ of potassium-phosphate buffer $(\mathrm{pH}-7.0)$ and it was centrifuged at $6000 \mathrm{rpm}$ for 15 minutes to collect the supernatant (enzyme extract). The assay mixture containing $1 \mathrm{~mL}$, $0.5 \mathrm{mM}$ ascorbic acid- potassium phosphate buffer $\left(50 \mathrm{mM}, \mathrm{p}^{\mathrm{H}}-7.0\right)$ solution, $1 \mathrm{~mL}$ of $\mathrm{H}_{2} \mathrm{O}_{2}$ $(0.1 \mathrm{mM})$ and $200 \mu \mathrm{L}$ of enzyme extract was measured at $290 \mathrm{~nm}$ for the determination of APOX by following the decrease in absorbance for 1 minute. The enzyme extract was added lastly to start the reaction.

The estimation of dehydroascorbate reductase (DHAR, EC 1.8.5.1) activity was done by following the process of Nakano and Asada (1981) with some modification [34]. $500 \mathrm{mg}$ of tissue was homogenized with $10 \mathrm{~mL}$ of $50 \mathrm{mM}$ potassium-phosphate buffer $\left(\mathrm{p}^{\mathrm{H}}-7.0\right)$ and then centrifuged at $5000 \mathrm{rpm}$ for 15 minutes in $4^{0} \mathrm{C}$ temperature). The enzyme extract was collected as supernatant. The enzyme extract $(1 \mathrm{~mL})$ was mixed with $0.5 \mathrm{~mL}$ of $50 \mathrm{mM}$ potassium-phosphate buffer (pH- 7.0), $0.1 \mathrm{~mL}$ of $2.5 \mathrm{mM} \mathrm{GSH}, 0.2 \mathrm{mM}$ DHA (0.2 mL) and 
$6420.1 \mathrm{mM}$ ethylenediamine tetra-acetic acid $(0.1 \mathrm{~mL})$ and reaction rates were measured by the increase in absorbance at $265 \mathrm{~nm}$ in 10 seconds and in 30 seconds after adding the enzyme.

644 Glutathione reductase (GR, EC 1.6.4.2) activity was measured according to Schaedle and Bassham (1977) [35]. $500 \mathrm{mg}$ of tissue was extracted with $10 \mathrm{~mL}, 50 \mathrm{mM}$ potassiumphosphate buffer $\left(\mathrm{p}^{\mathrm{H}}-7.2\right)$ and centrifuged at $5000 \mathrm{rpm}$ for 15 minutes. The enzyme extract was collected as supernatant and reaction mixture was prepared. The reaction mixture was contained $4 \mathrm{~mL}$ of $50 \mathrm{mM}$ potassium-phosphate buffer $\left(\mathrm{p}^{\mathrm{H}}-7.0\right)$, containing $2 \mathrm{mM} \mathrm{Na} 2$ ethylenediamine tetra-acetic acid, $0.15 \mathrm{mM} \mathrm{NADPH}$, and $0.5 \mathrm{mM}$ oxidized glutathione (GSSG) and $100 \mu \mathrm{L}$ homogenate $\left(7 \mathrm{mg}\right.$ protein $\left.\mathrm{mL}^{-1}\right)$. After 30 minutes of incubation NADPH oxidation was followed at $340 \mathrm{~nm}$. The actual activity was determined by subtracting the correction factor (absorbance of assay mixture without NADPH at $340 \mathrm{~nm}$ was taken) from the absorbance of reaction mixture. The enzyme activity in all cases was expressed as enzyme unit $\mathrm{g}^{-1} \mathrm{dm} \mathrm{min}^{-1}$ according to Fick and Qualset (1975) [36].

\section{Extraction and estimation of ascorbate and glutathione}

656

657

658

659

660

661

662

$1 \mathrm{~g}$ tissue was homogenized in $10 \mathrm{~mL}$ cold $5 \%$ metaphosphoric acid. After centrifugation at $15,000 \mathrm{~g}$ for $30 \mathrm{~min}$ at $4^{\circ} \mathrm{C}$, the supernatant was collected for analyses of ascorbate and glutathione. This extraction procedure was little modified from the method given by Gossett et al 1994 [37]. The measurement of total ascorbate and reduced ascorbate (AsA) contents were modified from the method of Law et al (1983) [38]. Total ascorbate contents were determined in a $3 \mathrm{~mL}$ mixture. Enzyme extract $(0.3 \mathrm{~mL})$ was mixed with $0.15 \mathrm{~mL} 10 \mathrm{mM}$ dithiothreitol and $0.75 \mathrm{~mL} 150 \mathrm{mM}$ phosphate buffer $(\mathrm{pH}$ 7.4) containing $5 \mathrm{mM}$ ethylenediamine tetra-acetic acid and was incubated at $25^{\circ} \mathrm{C}$ for $10 \mathrm{~min}$, followed by addition of $0.15 \mathrm{~mL}, 0.5 \%$ of N-ethylmaleimide. Then $10 \%$ trichloroacetic acid $(0.6 \mathrm{~mL}), 44 \%$ orthophosphoric acid $(0.6 \mathrm{~mL})$ and $0.6 \mathrm{~mL}$ of $4 \%$ of $\alpha, \alpha^{\prime}$-bipyridyl were added. Finally, $3 \%$ 
of $\mathrm{FeCl}_{3}$ was added and the mixture was incubated in $40^{\circ} \mathrm{C}$ for $40 \mathrm{~min}$ and the absorbance was detected at A525. AsA contents were determined by adding distilled water instead of dithiothreitol and N-ethylmaleimide and then followed the same method as above. Total and reduced contents were estimated from the standard curve of $0-100 \mu \mathrm{g} \mathrm{mL} \mathrm{m}^{-1} \mathrm{~L}-\mathrm{AsA}$ determined by the above method. Dehydro ascorbate (DHA) contents were calculated by the subtraction of AsA from total AsA.

Total glutathione contents were determined by the change in absorbance at $412 \mathrm{~nm}$ for 1 minute, according to the method reported by Zhang and Kirkham, 1996 [39]. The assay mixture contained $20 \mu \mathrm{L}$ of distilled water, $150 \mu \mathrm{L}$ of supernatant, $700 \mu \mathrm{L}$ of $0.3 \mathrm{mM}$ NADPH, $100 \mu \mathrm{L}$ of $6 \mathrm{mM}$ DTNB (dithiobis-2-nitrobenzoic acid) and $50 \mu \mathrm{L}$ of glutathione reductase (GR). The contents of glutathione (reduced form) were estimated from the standard curve of $0-30 \mu \mathrm{mol} \mathrm{mL} \mathrm{mL}^{-1}$ glutathione. After the removal of glutathione (GSH) by 2vinylpyridine derivative $(20 \mu \mathrm{L})$, glutathione disulfide (GSSG) contents were determined, and the glutathione (GSH) contents were calculated by the subtraction of glutathione disulfide (GSSG) contents from total glutathione contents.

In situ staining for visualization of superoxide and hydrogen peroxide in seedlings of IARCs exposed to PIDS

For the detection of superoxide and hydrogen peroxide the process of He et al (2009) was followed [40]. In case of superoxide the seeds of different stressed conditions as well as control set were incubated separately in $6 \mathrm{mM}$ nitroblue tetrazolium in $10 \mathrm{mM}$ TRIS-HCl buffer $\left(\mathrm{p}^{\mathrm{H}-7.4)}\right.$ at room temperature for 15 minutes. The accumulation of superoxide anion was detected by observing the dark blue colour as compared to untreated control set. Hydrogen peroxide was detected by soaking the stressed and untreated control seedlings in 
689

690

691

692

693

694

695

696

697

698

699

700

701

702

703

704

705

706

707

708

709

710

711

$0.42 \mathrm{mM}$ TMB $\left(3,5,3^{\prime} 5^{\prime}\right.$-tetramethylbenzidine) solution in $15 \mathrm{mM}$ TRIS-acetate buffer $\left(\mathrm{p}^{\mathrm{H}}\right.$ 5) for 2 hours. Blue-green colour can be monitored to indicate the accumulation of $\mathrm{H}_{2} \mathrm{O}_{2}$.

In situ localization of hydrogen peroxide by confocal microscopy in seedlings of indigenous aromatic rice cultivars (IARCs) exposed to post-imbibitional dehydration stress (PIDS)

The sample preparation was done by following the method of Kaur et al 2016 [41]. Root of 7 days old seedlings of experimental rice cultivars were dipped immediately in $10 \mu \mathrm{M}$ $\mathrm{H}_{2}$ DCFDA solution and kept at room temperature. After 2 hours samples were washed thrice with autoclaved milliQ water and slides were prepared with $20 \%$ glycerol. Aaccumulation of $\mathrm{H}_{2} \mathrm{O}_{2}$ in roots was identified by DCFDA staining and confocal microscopy using Leica application suite X software (microscope model number was Leica TCS SP8, laser scanning mode $488 \mathrm{~nm}$, emission at 505-530 nm, objective used was 20X) in differentially grown seedlings (7 days old) raised from post-imbibitional dehydration stress (-1.619 MPa) vis- $a$ vis their untreated control. Green fluorescence indicates presence of $\mathrm{H}_{2} \mathrm{O}_{2}$.

\section{Assessment of redox-biomarkers}

\section{Estimation of total ROS generation}

Total ROS estimation was performed by an in vitro assay. Seedling tissue were placed (30 mg) separately in $8 \mathrm{~mL}$ of $100 \mu \mathrm{M}$ 2', 7'-dichlorofluorescindiacetate (DCFDA, Sigma) solution (in $40 \mathrm{mM}$ TRIS-HCl buffer, $\mathrm{pH}-7.0$ ) at $30^{\circ} \mathrm{C}$. After $60 \mathrm{~min}$ Supernatants were taken and fluorescence was monitored in a spectrofluorometer (Hitachi, Model F-4500 FL Spectrophotometer) with excitation at $504 \mathrm{~nm}$ and emission at $525 \mathrm{~nm}$ [42]. To differentiate ROS from other long-lived substances able to react with DCFDA, additional controls were performed. For additional controls, seedling tissues were incubated without DCFDA for 60 min and then tissues were removed followed by addition of DCFDA which is 60 min before 
fluorescence was determined. This florescence values was subtracted from all readings to assess the fluorescence that depend on ROS. Corrections for auto-fluorescence were made by the inclusion in each experiment of parallel blanks, i.e., assay mixture without plant material.

\section{Extraction and estimation of superoxide $\left(\mathrm{O}_{2} \cdot^{-}\right)$and hydrogen peroxide $\left(\mathrm{H}_{2} \mathrm{O}_{2}\right)$ generation}

Superoxide was extracted and estimated by the process of Chaitanya and Naithani (1994) with some necessary modifications [43]. $500 \mathrm{mg}$ of tissues was homogenized in cold with 5 $\mathrm{mL}$ of $0.2 \mathrm{M}$ sodium phosphate buffer, $(\mathrm{pH} 7.2)$, with addition of diethyldithiocarbamate (10-

$\left.{ }^{3} \mathrm{M}\right)$ to inhibit superoxide dismutase (SOD) activity. The homogenates was immediately centrifuged at $3000 \mathrm{~g}$ at $4^{0} \mathrm{C}$ for $15 \mathrm{~min}$. In the supernatant, superoxide anion was measured by its capacity to reduce nitroblue tetrazolium $\left(2.5 \times 10^{-4} \mathrm{M}\right)$. The absorbance of the end product was measured at $540 \mathrm{~nm}$. Formation of superoxide was expressed as $\Delta \mathrm{A}_{540} \mathrm{~g}^{-1} \mathrm{dm}$.

In case of determination of hydrogen peroxide, the procedure of MacNevin and Uron (1953) was followed using titanic sulfate [44]. For this, $1 \mathrm{~g}$ of tissue was extracted with $5 \mathrm{~mL}$ of cold acetone and filtered through Whatman No.1 filter paper and volume made up to $10 \mathrm{~mL}$ with distilled water. Now $1 \mathrm{~mL}$ of $5 \%$ titanic sulfate (in $20 \% \mathrm{H}_{2} \mathrm{SO}_{4}$ ) was added to this, which was followed by addition of $2 \mathrm{~mL}$ of concentrated $\mathrm{NH}_{4} \mathrm{OH}$ and finally centrifuged at $6000 \mathrm{rpm}$ for 10 minutes. Pellet obtained was washed with $5 \mathrm{~mL}$ of acetone (thrice) and then centrifuged at 5000rpm for 10 minutes. Then the pellet was dissolved in $3 \mathrm{~mL}$ of $2(\mathrm{~N}) \mathrm{H}_{2} \mathrm{SO}_{4}$ and absorbance was taken at $420 \mathrm{~nm}$ against a blank.

Assessment of radical scavenging property or total antioxidant capacity (DPPH radical scavenging property)

For determination of DPPH (2, 2'-diphenyl-1-pycryl hydrazyl) free radical scavenging activity the process of Mensor et al (2001) was followed with little modification [45]. 1.5 
gram of dry sample (seedling tissues kept at $45^{\circ} \mathrm{C}$ for two days) was extracted with $30 \mathrm{~mL}$ $80 \%$ methanol at $28^{\circ} \mathrm{C}$ for 24 hours in shaking incubator. Extracts were centrifuged at 3500 rpm for 20 minutes at $4^{\circ} \mathrm{C}$. Supernatant was collected and filtered and filtrate was used for DPPH radical scavenging activity. For estimating the radical scavenging activity $1 \mathrm{~mL}$ sample was mixed with $3 \mathrm{~mL}$ DPPH $\left(0.04 \mathrm{mg} \mathrm{mL}^{-1}\right.$ ethanol) and incubated for 30 minutes in darkness and then absorbance was taken at $517 \mathrm{~nm}$. Total antioxidant capacity (TAC) was calculated as:

$\operatorname{TAC}(\%)=\left[1-\frac{\mathrm{Ai}-\mathrm{Aj}}{\mathrm{Ac}}\right]_{\times 100}$

Where $A_{i}=1 \mathrm{~mL}$ sample $+3 \mathrm{~mL}$ DPPH; $A_{j}=1 \mathrm{~mL}$ sample $+3 \mathrm{~mL}$ ethanol $; A_{c}=1 \mathrm{~mL}$ ethanol $+3 \mathrm{~mL}$ DPPH

\section{Extraction and estimation of thiobarbituric acid reactive substances}

To estimate membrane lipid peroxidation, test for thiobarbituric acid reactive substances (TBARS) was performed using the procedure of Heath and Packer (1968) [46]. The membrane lipid peroxidation of drought-stressed as well as control tissues was estimated in terms of malondialdehyde accumulation. $200 \mathrm{mg}$ of sample was homogenized in $5 \mathrm{~mL} 0.1 \%$ trichloroacetic acid and then centrifuged at 10,000 rpm for 15 minutes and finally supernatant was taken. To $1 \mathrm{~mL}$ of supernatant $3 \mathrm{~mL}$ of $5 \%$ trichloroacetic acid containing $1 \%$ thiobarbituric acid (TBA) was added and heated in a hot water bath for 30 minutes and cooled quickly in cold water bath. It was finally centrifuged at 10,000 rpm for 10 minutes. The absorbance of the supernatant was measured at $530 \mathrm{~nm}$. The concentration of TBARS was measured from its extinction coefficient of $155 \mu \mathrm{M} \mathrm{cm}^{-1}$. The non-specific turbidity was corrected by subtracting $\mathrm{A}_{600}$ from $\mathrm{A}_{530}$ value. The TBARS content is finally expressed in $\mathrm{n}$ mol $\mathrm{g}^{-1}$ dry mass of tissue. 
759

760

761

762

763

764

765

766

767

768

769

770

771

772

773

774

775

776

777

778

779

Lipoxygenase was estimated according to the method of Peterman and Siedow (1985) [47]. Enzyme was extracted by centrifugation at $5000 \mathrm{rpm}$ and re-centrifugation at $17000 \mathrm{rpm}$ in cold using $50 \mathrm{mM}$ sodium-phosphate buffer $\left(\mathrm{p}^{\mathrm{H}}-6.5\right)$. Then the assay mixture was made containing enzyme extract, $1.3 \mathrm{mM}$ linoleic acid and $1.65 \mathrm{mM}$ sodium-phosphate buffer $\left(\mathrm{p}^{\mathrm{H}}\right.$ 6.5). After incubation of the assay mixture for 1 hour at $25^{\circ} \mathrm{C}$, absorbance was taken at 234 nm.

\section{Extraction and estimation of hydroperoxide}

Hydroperoxide was estimated by following the method of Devasagayam et al (2003) with some necessary modifications [48]. Tissue was extracted with $150 \mathrm{mM}$ tris- $\mathrm{HCl}\left(\mathrm{p}^{\mathrm{H}}-6.8\right)$. The assay mixture contained $0.25 \mathrm{mM} \mathrm{H}_{2} \mathrm{SO}_{4}, 250 \mathrm{mM}$ ammonium ferrous sulphate, $100 \mathrm{mM}$ xylenol orange, $4 \mathrm{mM}$ BHT (in 90\% methanol) and an aliquot of sample extract. After incubation at room temperature for 30 minutes, triphenyl phosphine $(100 \mathrm{mM})$ was added to the reaction mixture to specify the reduction of hydroperoxide, distinguished from hydrogen peroxide [49]. Then the absorbance was taken at $560 \mathrm{~nm}$.

\section{Extraction and estimation of conjugated diene}

The process of Buege and Aust (1978) was followed for the estimation of conjugated diene [50]. Tissue was extracted with chloroform: methanol mixture $(2: 1)$ followed by vigorous vortex mixing and then centrifuged for 10 minutes at $2000 \mathrm{rpm}$. After centrifugation the lower chloroform layer was collected and dried at $45^{\circ} \mathrm{C}$ under steam of nitrogen. The obtained residue was dissolved in $7 \mathrm{~mL}$ of cyclo-hexane and absorbance was taken at 230 $\mathrm{nm}$. 
782 Oxidative damage to proteins was estimated as the content of carbonyl groups following the procedure of Jiang and Zhang (2001) [51]. $500 \mathrm{mg}$ of tissues (seedling) were homogenized with $3 \mathrm{~mL}$ of $50 \mathrm{mM}$ potassium phosphate buffer ( $\mathrm{pH}$ 7.0) containing $1 \mathrm{mM}$ ethylenediamine tetra-acetic acid, $1 \mathrm{mM}$ PMSF (phenyl methyl sulfonyl fluoride), $10 \mathrm{mM}$ dithithreitol and 5

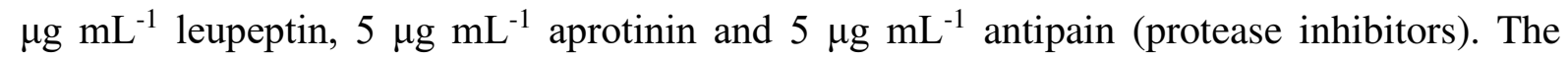
homogenate was centrifuged at $15000 \times \mathrm{g}$ for $25 \mathrm{~min}$ and the supernatant was made free from contaminating nucleic acids by treatment with streptomycin sulfate $50 \mu \mathrm{g} \mathrm{mL}^{-1}$. An equal volume of $10 \mathrm{mM}$ dinitrophenylhydrazine in $2 \mathrm{M} \mathrm{HCl}$ was added to supernatant containing the oxidized protein. These were allowed to stand in the dark at room temperature for 1 hour, with vortex every $10 \mathrm{~min}$. Samples were precipitated with trichloroacetic acid (TCA; 20\% final concentration) and centrifuged in a table- top micro centrifuge at $10,000 \mathrm{rpm}$ for 5 minutes. The supernatants were discarded and the protein pellets were washed twice more with trichloroacetic acid and then washed three times with $1 \mathrm{~mL}$ portions of ethanol/ethylacetate (1:1) to remove any free dinitrophenylhydrazine. The protein samples were re-suspended in $1 \mathrm{ml}$ of $6 \mathrm{M}$ guanidine hydrochloride (dissolved in $20 \mathrm{mM}$ phosphate buffer, $\mathrm{pH} 2.3$ ) at $37^{\circ} \mathrm{C}$ for $15 \mathrm{~min}$ with vortex mixing. Carbonyl contents were determined from the absorbance at $370 \mathrm{~nm}$ using a molar absorption coefficient of $22 \mathrm{mM} \mathrm{cm}^{-1}$.

\section{Germination and early growth phenotypes of indigenous aromatic rice cultivars} (IARCs) exposed to post-imbibitional dehydration stress (PIDS)

Germination and early growth performances of PIDS-raised IARCs vis-a-vis their untreated control were assessed in terms of $\mathrm{T}_{50}$ value, relative germination performance (RGP), coefficient of velocity of germination (CVG), germination rate index (GRI), mean 
806 T50 value: Time (In hour) of $50 \%$ germination of seeds sown

807 Relative germination performance (RGP):

808

$\frac{\text { Percentage of germination under treatment }}{\text { Percentage of germination under control }} \times 100$

809 Coefficient of velocity of germination $(\mathrm{CVG})$ :

810

$$
\frac{\sum N i}{\sum(N i T i)} \times 100
$$

811 Germination Rate Index (GRI):

$812 \sum\left(\frac{N i}{i}\right)$

813 Mean Germination Time (MGT):

$814 \quad \frac{\Sigma(N i T i)}{\sum N i}$

815 Mean Daily Germination (MDG):

$816 \quad \frac{N}{T}$

817 Relative growth index (RGI):

average dry mass of ten treated seedlings

average dry mass of ten control seedlings $\times 100$

819 Vigor index (VI):

Mean shoot length + Mean root length

820

\footnotetext{
Percentage of final germination
} 
822 Relative water content was measured by following the method of Barrs and Weatherley

823 (1962) [55]. 10 fresh seedlings of equal length and diameter (4mm) were weighed and floated 824 on distilled water at $25^{\circ} \mathrm{C}$ for 4 hours. Then the seedlings were blotted and weighed again 825 (Turgid weight). After that, those seedlings were kept for oven dry for 24 hours at $80^{\circ} \mathrm{C}$ and 826 final weight was taken. The relative water content was calculated by the following formula:

RWC $=\frac{\text { Fresh weight }- \text { Dry weight }}{\text { Turgid weight }- \text { Dry weight }} \times 100$

\section{Comparative transcriptomic investigation}

Seeds of the experimental IARCs which were screened as drought sensitive (Jamainadu) and drought tolerant (Badshabhog) one, based on quality redox-parameters and physiological phenotyping was imposed with -1.619 MPa PIDS (with PEG-6000) for comparative transcriptome analysis from cDNA libraries prepared from total RNA extracted from the corresponding seedlings. Seven days old PIDS-raised seedlings were collected and planted directly into liquid nitrogen and stored at $-80^{\circ} \mathrm{C}$ for further analysis.

RNA isolation, cDNA library construction, Illumina sequencing, read mapping, differential gene expression analysis, KEGG pathway analysis and gene ontology $(G O)$ analysis

Isolation, Qualitative and quantitative analysis of RNA

839 Total RNA was isolated from samples using TRIzol reagent according to manufacturer's 840 instruction (Invitrogen, USA). The quality of the isolated RNA was checked on $1 \%$ 841 Formaldehyde Denaturing Agarose gel and quantified using Qubit® 2.0 Fluorometer. 
843 The libraries were prepared from samples with input total RNA $\sim 1 \mu \mathrm{g}$ using Illumina TruSeq

844 Stranded mRNA Library Preparation Kit as per the manufacturer's protocol at Xcelris Labs 845 Limited, Ahmedabad, India. Briefly, total RNA was subjected to Oligo dT beads to enrich 846 mRNA fragments, then subjected to purification, fragmentation and priming for cDNA 847 synthesis. The fragmented mRNA was converted into first-strand cDNA, followed by second-strand cDNA synthesis, A-tailing, adapter-index ligation and finally amplified by 849 recommended number of PCR cycles. Library quality and quantity check was performed 850 using Agilent DNA High Sensitivity Assay Kit.

851 I also tested whether there was any significant effect of dissimilar read sizes in the present 852 analysis by generating MA plot.

Quantity and quality check (QC) of library on Bioanalyzer 2100

854 The amplified libraries were analyzed on Bioanalyzer 2100 (Agilent Technologies) using 855 High Sensitivity (HS) DNA chip as per manufacturer's instructions.

\section{Cluster Generation and Sequencing}

857 After obtaining the Qubit concentration for the library and the mean peak size from Bioanalyzer profile, library was loaded into Illumina platform for cluster generation and sequencing. Paired-End sequencing allows the template fragments to be sequenced in both

860 the forward and reverse directions. The library molecules bind to complementary adapter 861 oligos on paired-end flow cell. The adapters were designed to allow selective cleavage of the forward strands after re-synthesis of the reverse strand during sequencing. The copied reverse strand was then used to sequence from the opposite end of the fragment. 
865 Reference guided transcript assembly was performed for all the samples, first by mapping 866 HQ reads on reference genome using hisat2 (v 2.2.1) and then performing transcript assembly 867 by StringTie (v 2.1.4). A consensus set of transcripts was obtained using SringTie merge 868 function which merges together all the gene structures found in any of the samples. 869 Transcript abundance was then estimated using merged transcript consensus again using 870 StringTie and read counts thus obtained for each transcript were taken as input for differential 871 expression analysis using edgeR package. GO and pathway analysis of the differentially 872 expressed transcripts were performed using UniprotKB and KEGG-KAAS server respectively. Overall bioinformatics workflow is graphically represented in figure 17.

\section{Statistical analysis}

878 Each experiment was carried out twice at different times and had three replicates for each treatment. Results calculated as mean of three replicates \pm standard error. Statistical analysis of the data for significance, the "t-test, paired two samples for means" was done using Microsoft Excel 2010, which shows the significant variations between untreated control and different magnitude of post-imbibitional dehydration stress-raised seedlings. 
GO: gene ontology; KEGG: kyoto encyclopedia of genes and genomes; IARC: indigenous 887 aromatic rice cultivar; ABA: abscisic acid; JA: jasmonic acid; SA: salicylic acid; IAA: 888 indole-3-acetic acid; GA: gibberellic acid; PIDS: post-imbibitional dehydration stress; PEG: polyethylene glycol; ROS: reactive oxygen species; TBARS: thiobarbituric acid reactive substances; MPa: megapascal; GB: gigabyte; GTF: gene transfer format; GFF: general feature format; DGE: differential gene expression; DEG: differential expression of genes; KAAS: KEGG automatic annotation server; $\log 2 \mathrm{FC}$ : $\log 2$ fold change; BS: brassinosteroid; CRSMF:

893 Crop Research and Seed Multiplication Farm; APOX: ascorbate peroxidase; DHAR: 894 dehydroascorbate reductase; GR: glutathione reductase; TAC: total antioxidant capacity; 895 AsA: reduced ascorbate; GSSG: glutathione disulfide; GSH: glutathione; RGP: relative 896 germination performance; CVG: coefficient of velocity of germination; GRI: germination 897 rate index; MGT: mean germination time; MDG: mean daily germination; RGI: relative 898 growth index; VI: vigor index; QC: quality check.

\section{Ethics approval and consent to participate}

900 Not applicable.

\section{Consent for publication}

902 Not applicable. 
904 Seeds of two experimental indigenous aromatic rice cultivars [IARCs Oryza sativa L.,

905 Cultivars Jamainadu and Badshabhog were collected from Chinsurah Rice Research Station,

906 Chinsurah, Government of West Bengal, India.

907 Competing interests

908 Not applicable.

$909 \quad$ Funding

910 University of Burdwan, Government of West Bengal, India funded the Research Fellowship

911 of ND. Instrumentation support and other infrastructural support is given by the sanctioned 912 project of DST-FIST, Govt. of India to the Department of Botany, The University of 913 Burdwan, West Bengal, india.

\section{Authors' contributions}

915 Conceptualization: SB; Methodology: ND; Formal analysis and investigation: ND; Writing 916 original draft preparation: SB; Writing : ND SB; Funding acquisition: SB, ND; Resources:

917 SB; Supervision: SB. All authors read and approved the final manuscript.

918 Acknowledgements

919 ND acknowledges Government of West Bengal for providing State Funded Fellowship [No. $920 \mathrm{FC}(\mathrm{Sc}.) / \mathrm{RS} / \mathrm{SF} / \mathrm{BOT} . / 2014-15 / 103 /(3) / 1(3)]$.

921 SB and ND acknowledge DST-FIST, Government of India for instrument facility 922 (No./SRFST/LS-I/2018/188 (C), Department of Botany, BU).We sincerely acknowledge 923 Xcelris Labs Limited, Ahmedabad, Gujarat, India for RNA-seq analysis. 
ND, Senior Research Fellow, Department of Botany, The University of Burdwan, Burdwan,

926 West Bengal.

927 SB, Professor and Coordinator, UGC Centre for Advanced Study, Department of Botany, The

928 University of Burdwan, Burdwan, West Bengal.

\section{References}

1. Calpe C. International trade in rice: recent developments and prospects. IRRI. 2005;492.

2. Bradbury L, Gillies S, Brushett D, Waters D, Henry R. Inactivation of an amino aldehyde dehydrogenase is responsible for fragrance in rice. Plant Mol Biol. 2008;68(4-5):439-49.

3. FAO: The State of Food Insecurity in the World. Rome. http://www.fao.org(2009). Accessed 31 Dec 2020.

4. Zhang F, Zhai H, Paterson A, Xu J, Gao Y, Zheng T, Wu R, Fu B, Ali J, Li Z. Dissecting genetic networks underlying complex phenotypes: the theoretical framework. PloS one. 2011;6(1):e14541.

5. Jain M. Next-generation sequencing technologies for gene expression profiling in plants. Brief Funct Genomics. 2011;11(1):63-70.

6. Deb D. (2005) Seeds of traditional, seeds of future: folk rice varieties of Eastern India. 
7. Bhattacharjee S, Dey N. Redox metabolic and molecular parameters for screening drought tolerant indigenous aromatic rice cultivars. Physiol Mol Biol Plants. 2018;24(1):7-23.

8. Dey N, Bhattacharjee S. Accumulation of phenolic compounds and osmolytes under dehydration stress and their implication in redox regulation: A biochemical basis for screening Indigenous Aromatic Rice Cultivars. Rice Sci. 2020;27(4):329-44.

9. Petrov V, Hille J, Mueller-Roeber B, Gechev TS. ROS-mediated abiotic stressinduced programmed cell death in plants. Plant Physiol. 2015;6:69.

10. Zu X, Lu Y, Wang Q, Chu P, Miao W, Wang H, La H. A new method for evaluating the drought tolerance of upland rice cultivars. The Crop J. 2017;5:488-98.

11. Yang X, Wang B, Chen L, Li P, Cao C. The different influences of drought stress at the flowering stage on rice physiological traits, grain yield, and quality. Scientific Reports. 2019;9(7):3742.

12. Mittler R. ROS are good. Trends Plant Sci. 2017;22(1):11-19.

13. Chen J, Nolan TM, Ye H, Zhang M, Tong H, Xin P, Chu J, Chu C, Li Z, Yin Y. Arabidopsis WRKY46, WRKY54, and WRKY70 transcription factors are involved in brassinosteroid-regulated plant growth and drought responses. The Plant cell. 2017;29(6):1425-39; doi:10.1105/tpc.17.00099.

14. Urano K, Maruyama K, Jikumaru Y, Kamiya YJ, Yamaguchi-Shinozaki K, Shinozaki K. Analysis of plant hormone profiles in response to moderate dehydration stress. The Plant J. 2017;90(1):17-36. 
15. Xiong H, Yu J, Miao J, Li J, Zhang H, Wang X, Liu P, Zhao Y, Jiang C, Yin Z, Li Y, Guo Y, Fu B, Wang W, Li ZK, Ali J, Li ZH. Natural variation in OsLG3 increases drought tolerance in rice by inducing ROS scavenging. Plant Physiol. 2018;178(1):451-67.

16. Wang W, Mauleon R, Hu Z, Chebotarov D, Tai S, Wu Z, Li M, Zheng T, Fuentes RR, Zhang F, et al. Genomic variation in 3,010 diverse accessions of Asian cultivated rice. Nature. 2018;557:43-9.

17. Bang SW, Lee D-K, Jung H, Chung PJ, Kim YS, Choi YD, Suh J-W, Kim J-K. Overexpression of $O s T F 1 L$, a rice HD-Zip transcription factor, promotes lignin biosynthesis and stomatal closure that improves drought tolerance. Plant Biotechnol J. 2019;17:118-31.

18. Duan F, Ding J, Lee D, Lu X, Feng Y, Song W. Overexpression of SoCYP85A1, a spinach cytochrome p450 gene in transgenic tobacco enhances root development and drought stress tolerance. Front Plant Sci. 2017;8:1909.

19. Mir RR, Zaman-Allah M, Sreenivasulu N, Trethowan R, Varshney RK. Integrated genomics, physiology and breeding approaches for improving drought tolerance in crops. TheorAppl Genet. 2012;125:625-45.

20. Zagorchev L, Teofanova D, Odjakova M. Ascorbate-glutathione cycle: Controlling the redox environment for drought tolerance. In: Hossain MA, Wani SH, Bhattacharjee S, Burritt DJ, Phan Tran L-S, editors. Drought stress tolerance in plants, volume 1. Switzerland:Spinger Nature; 2016. p. 187-226. 
21. Abbas S, Ahmad S, Sabir S, Shah A. Detection of drought tolerant sugarcane genotypes (Saccharum officinarum) using lipid peroxidation, antioxidant activity, glycinebetaine and proline contents. J Soil Sci Plant Nutr. 2014;14:233-43. characterization and sequencing-based identification of drought-responsive genes in potato. Mol Biol Rep. 2014;41(1):505-17.

23. Zivcak M, Brestic M, Sytar O. Osmotic adjustment and plant adaptation to drought stress. In: Hossain MA, Wani SH, Bhattacharjee S, Burritt DJ, Phan Tran L-S, editors. Drought stress tolerance in plants, volume 1. Switzerland:Springer Nature; 2016. p. 105-43.

24. Lin D, Xiao M, Zhao J, Li Z, Xing B, Li X, Kong M, Li L, Zhang Q, Liu Y, Chen H, Qin $\mathrm{W}, \mathrm{Wu} \mathrm{H}$, Chen S. An overview of plant phenolic compounds and their importance in human nutrition and management of type 2 diabetes. Molecules. 2016;21(10):1374; doi:10.3390/molecules21101374.

25. Simon S, Korukkanvilakath SS. Screening for osmotic stress responses in rice varieties under drought condition. Rice Sci. 2017;24(5):253-63.

26. Lenka SK, Katiyar A, Chinnusamy V, Bansal KC. Comparative analysis of droughtresponsive transcriptome in Indica rice genotypes with contrasting drought tolerance. Plant Biotechnol J. 2011;9(13):315-27.

27. Cal AJ, Liu D, Mauleon R, Hsing YC, Serraj R. Transcriptome profiling of leaf elongation zone under drought in contrasting rice cultivars. PLoS ONE. 2013;8:e54537; doi:10.1371/journal.pone.0054537. 
28. Yang Z, Dai Z, Lu R, Wu B, Tang Q, Xu Y, Cheng C, Su J. Transcriptome analysis of two species of jute in response to polyethylene glycol (PEG)-induced drought stress. Sci Rep. 2017;7:16565.

29. Luo Y, Pang D, Jin M, Chen J, Kong X, Li W, Chang Y, Li Y, Wang Z. Identification of plant hormones and candidate hub genes regulating flag leaf senescence in wheat response to water deficit stress at the grain-filling stage. Plant direct. 2019;3(11):1-23.

30. Ereful NC, Liu L-Y, Greenland A, Powell W, Mackay I, Leung H. RNA-seq reveals differentially expressed genes between two indica inbred rice genotypes associated with drought-yield $\quad$ QTLs. Agronomy. 2020;10(5):621; doi:10.3390/agronomy10050621.

31. Toni B, Monfared HH, Isa MNM, Isa NM, Ismail I, Zainal Z. RNA-seq data of Oryza sativa cultivar Kuku Belang under PEG treatment. Data in Brief. 2017;14:260-6.

32. de Carvalho MHC. Drought stress and reactive oxygen species: Production, scavenging and signaling. Plant Signal Behav. 2008;3:156-65.

33. Ullah A, Manghwar H, Shaban M, Khan AH, Akbar A, Ali U, Ali E, Fahad S. Phytohormones enhanced drought tolerance in plants: A coping strategy. Environ Sci Pollut Res. 2018;25:33103-18.

34. Nakano Y, Asada K. Hydrogen peroxide is scavenged by ascorbate specific peroxidase in spinach chloroplasts. Plant Cell Physiol. 1981;22:867-80.

35. Schaedle M, Bassham JA. Chloroplast glutathione reductase. Plant Physiol. 1977;59(5):1011-2. 
36. Fick NG, Qualset CD. Genetic control of plant amylase activity. Proc Natl Acad Sci. $1975 ; 72: 852-62$.

37. Gossett DR, Millhollon ER, Lucas MC. Antioxidant response to $\mathrm{NaCl}$ stress in salt tolerant and salt-sensitive cultivars of cotton. Crop Sci. 1994;34:706-14.

38. Law MY, Charles SA, Halliwell B. Glutathione and ascorbic acid in spinach (Spinacia oleracea) chloroplasts. Biochem J. 1983;210(3):899-903.

39. Zhang J, Kirkham MB. Antioxidant responses to drought in sunflower and sorghum seedlings. New Phytol. 1996;132:361-73.

40. He L, Gao Z, Li R. Pretreatment of seed with $\mathrm{H}_{2} \mathrm{O}_{2}$ enhances drought tolerance of wheat seedlings. Afr J Biotechnol. 2009;8(22):6151-7.

41. Kaur N, Sharma I, Kirat K, Pati PK. Detection of reactive oxygen species in Oryza sativa L. (Rice). Bio-protocol. 2016;6(24); doi:10.21769/BioProtoc.2061.

42. Simontacchi M, Caro A, Fraga CG, Puntarulo S. Oxidative stress affects $\alpha$-tocopherol content in soyabean embryonic axes upon imbibitions. Plant Physiol. 1993;103:94953.

43. Chaitanya KSK, Naithani SC. Role of superoxide, lipid peroxidation and superoxide dismutase in membrane perturbation during loss of viability of Shorea robusta Gaertn. f. New Phytol. 1994;126(4):623-7.

44. MacNevin WM, Uron PF. Spectrum of hydrogen peroxide from organic hydroperoxides. Anal Chem. 1953;25:1760-1. 
45. Mensor LL, Menezes FS, Leitao GG, Reis AS, dos Santos TC, Coube CS, Leitao SG. Screening of Brazilian plant extracts for antioxidant activity by the use of DPPH free radical method. Phytother Res. 2001;15:127-30.

46. Heath RL, Packer L. Photoperoxidation in isolated chloroplasts. I. Kinetics and stoichiometry of fatty acid peroxidation. Arch Biochem Biophys. 1968;125:189-98.

47. Peterman K, Siedow JN. Behavior of lipoxygenase during establishment, senescence, and rejuvenation of soybean cotyledons. Plant physiol. 1985;78(4):690-5.

48. Devasagayam TP, Boloor KK, Ramasarma T. Methods for estimating lipid peroxidation: an analysis of merits and demerits. Ind $\mathrm{J}$ Biochem Biophys. $2003 ; 40(5): 300-8$.

49. Nourooz-Zadeh J, Tajaddini-Sarmadi J, Wolff SP. Measurement of plasma hydroperoxide concentrations by the ferrous oxidation-xylenol orange assay in conjunction with triphenyl phosphine. Anal Biochem. 1994;220(2):403-9.

50. Buege JA, Aust SD. Microsomal lipid peroxidation. Methods Enzymol. 1978;52:30210.

51. Jiang M, Zhang J. Effect of abscisic acid on active oxygen species, antioxidative defense system and oxidative damage in leaves of maize seedlings. Plant Cell Physiol. 2001;42:1265-73.

52. Rubio-Casal AE, Castillo JM, Luque CJ, Figueroa E. Influence of salinity on germination and seeds viability of two primary colonizers of Mediterranean salt pans. J Arid Environments. 2003;53(2):145-54. 
1080

1081

1082

1083

1084

1085

1086

1087 Table 12: KEGG pathway stats for differentially expressed transcripts

\begin{tabular}{|c|c|}
\hline Pathway & Count \\
\hline
\end{tabular}
association interpretation of resulting data. J Proc-Royal Society of New South Wales. 2005;138:65-75.

54. Bhattacharjee S. Calcium-dependent signaling pathway in heat induced oxidative injury in Amaranthus lividus. Biol Plant. 2008;52:1137-40.

55. Barrs HD, Weatherley PE. A re-examination of the relative turgidity technique for estimating water deficits in leaves. Aust J Biol Sci. 1962;15:413-28. 


\begin{tabular}{|c|c|}
\hline 09100 Metabolism & 5191 \\
\hline 09101 Carbohydrate metabolism & 1244 \\
\hline 09102 Energy metabolism & 480 \\
\hline 09103 Lipid metabolism & 651 \\
\hline 09104 Nucleotide metabolism & 183 \\
\hline 09105 Amino acid metabolism & 783 \\
\hline 09106 Metabolism of other amino acids & 282 \\
\hline 09107 Glycan biosynthesis and metabolism & 234 \\
\hline 09108 Metabolism of cofactors and vitamins & 347 \\
\hline 09109 Metabolism of terpenoids and polyketides & 219 \\
\hline 09110 Biosynthesis of other secondary metabolites & 463 \\
\hline 09111 Xenobiotics biodegradation and metabolism & 305 \\
\hline 09120 Genetic Information Processing & 2396 \\
\hline 09121 Transcription & 378 \\
\hline 09122 Translation & 947 \\
\hline 09123 Folding, sorting and degradation & 733 \\
\hline 09124 Replication and repair & 338 \\
\hline 09130 Environmental Information Processing & 1875 \\
\hline 09131 Membrane transport & 40 \\
\hline 09132 Signal transduction & 1834 \\
\hline 09133 Signaling molecules and interaction & 1 \\
\hline 09140 Cellular Processes & 1837 \\
\hline 09141 Transport and catabolism & 840 \\
\hline 09142 Cell motility & 57 \\
\hline 09143 Cell growth and death & 723 \\
\hline 09144 Cellular community - eukaryotes & 136 \\
\hline 09145 Cellular community - prokaryotes & 81 \\
\hline 09150 Organismal Systems & 824 \\
\hline 09149 Aging & 231 \\
\hline
\end{tabular}




\begin{tabular}{|l|l|}
\hline 09158 Development and regeneration & 127 \\
\hline 09159 Environmental adaptation & 466 \\
\hline 09180 Brite Hierarchies & $\mathbf{9 8 8 2}$ \\
\hline 09181 Protein families: metabolism & 1674 \\
\hline 09182 Protein families: genetic information processing & 6454 \\
\hline 09183 Protein families: signaling and cellular processes & 1754 \\
\hline 09190 Not Included in Pathway or Brite & $\mathbf{5 3 0}$ \\
\hline 09191 Unclassified: metabolism & 403 \\
\hline 09192 Unclassified: genetic information processing & 15 \\
\hline 09193 Unclassified: signaling and cellular processes & 57 \\
\hline 09194 Poorly characterized & 55 \\
\hline
\end{tabular}

1090 Table 13: Comparative pathway count of uniquely significant up-regulated DEG patheay in 1091 PIDS-raised experimental IARCs Jamainadu (SBND1) and Badshabhog (SBND2)

\begin{tabular}{|l|l|l|l|}
\hline \multicolumn{2}{|l|}{09100 Metabolism } & $\begin{array}{c}\text { Count - } \\
\text { SBND1 }\end{array}$ & $\begin{array}{c}\text { Count - } \\
\text { SBND2 }\end{array}$ \\
\hline & $\begin{array}{l}09101 \text { Carbohydrate } \\
\text { metabolism }\end{array}$ & 70 & 83 \\
\cline { 2 - 4 } & 09102 Energy metabolism & 27 & 19 \\
\hline & 09103 Lipid metabolism & 34 & 54 \\
\hline $\begin{array}{l}\text { 09104 Nucleotide metabolism } \\
\text { 09105 Amino acid metabolism }\end{array}$ & 39 & 49 \\
\hline $\begin{array}{l}\text { 09106 Metabolism of other } \\
\text { amino acids }\end{array}$ & 17 & 19 \\
\hline $\begin{array}{l}\text { 09107 Glycan biosynthesis and } \\
\text { metabolism }\end{array}$ & 12 & 18 \\
\hline $\begin{array}{l}\text { 09108 Metabolism of cofactors } \\
\text { and vitamins }\end{array}$ & 18 & 22 \\
\hline
\end{tabular}




\begin{tabular}{|c|c|c|c|}
\hline & $\begin{array}{l}09109 \quad \text { Metabolism } \\
\text { terpenoids and polyketides }\end{array}$ & 16 & 20 \\
\hline & $\begin{array}{l}09110 \text { Biosynthesis of other } \\
\text { secondary metabolites }\end{array}$ & 26 & 27 \\
\hline & 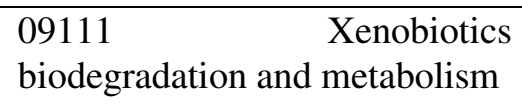 & 15 & 5 \\
\hline \multirow{4}{*}{$\begin{array}{l}09120 \text { Genetic Information } \\
\text { Processing }\end{array}$} & 09121 Transcription & 19 & 28 \\
\hline & 09122 Translation & 36 & 50 \\
\hline & $\begin{array}{l}09123 \text { Folding, sorting and } \\
\text { degradation }\end{array}$ & 43 & 47 \\
\hline & 09124 Replication and repair & 14 & 26 \\
\hline \multirow{2}{*}{$\begin{array}{l}09130 \quad \text { Environmental } \\
\text { Information Processing }\end{array}$} & 09131 Membrane transport & 4 & 3 \\
\hline & 09132 Signal transduction & 122 & 90 \\
\hline \multirow{5}{*}{09140 Cellular Processes } & 09141 Transport and catabolism & 35 & 75 \\
\hline & 09142 Cell motility & 3 & 2 \\
\hline & 09143 Cell growth and death & 35 & 36 \\
\hline & $\begin{array}{l}09144 \text { Cellular community - } \\
\text { eukaryotes }\end{array}$ & 14 & 2 \\
\hline & $\begin{array}{l}09145 \text { Cellular community - } \\
\text { prokaryotes }\end{array}$ & 7 & 3 \\
\hline \multirow{3}{*}{09150 Organismal Systems } & 09149 Aging & 12 & 10 \\
\hline & $\begin{array}{l}09158 \text { Development and } \\
\text { regeneration }\end{array}$ & 15 & 6 \\
\hline & $\begin{array}{ll}09159 & \text { Environmental } \\
\text { adaptation } & \end{array}$ & 33 & 26 \\
\hline \multirow{3}{*}{09180 Brite Hierarchies } & $\begin{array}{l}09181 \text { Protein families: } \\
\text { metabolism }\end{array}$ & 106 & 108 \\
\hline & $\begin{array}{l}09182 \text { Protein families: genetic } \\
\text { information processing }\end{array}$ & 352 & 450 \\
\hline & $\begin{array}{l}09183 \quad \text { Protein families: } \\
\text { signaling and cellular processes }\end{array}$ & 91 & 115 \\
\hline \multirow{2}{*}{$\begin{array}{l}09190 \text { Not Included in } \\
\text { Pathway or Brite }\end{array}$} & Unclassified: & 18 & 24 \\
\hline & $\begin{array}{l}09192 \text { Unclassified: genetic } \\
\text { information processing }\end{array}$ & 0 & 1 \\
\hline
\end{tabular}




\begin{tabular}{|l|l|l|l|} 
& $\begin{array}{l}09193 \text { Unclassified: signaling } \\
\text { and cellular processes }\end{array}$ & 4 & 1 \\
\cline { 2 - 5 } & 09194 Poorly characterized & 6 & 4 \\
\hline Total result & & $\mathbf{1 2 6 0}$ & $\mathbf{1 4 3 6}$ \\
\hline
\end{tabular}

1092

1093

1094

1095

1096

1097

1098

1099

1100

1101

1102

1103

1104

1105

1106

$1107 \quad$ Figure legends 
1108

1109

1110

1111

1112

1113

1114

1115

1116

1117

1118

1119

1120

1121

1122

1123

1124

1125

1126

1127

Fig1: Comparative representation of the status of Halliwell-Asada pathway in postimbibitional dehydration stress (PIDS)-raised IARCs, Jamainadu (A) and Badshabhog (B) vis-a-vis their untreated control (Unt. Cont.).

Fig2: In situ localization of hydrogen peroxide in roots observed through laser confocal microscopy (A \& B) and visualization of hydrogen peroxide through TMB staining (C \& D) and superoxide through NBT staining (E \& F) in post-imbibitional dehydration stress [PIDS (PEG-6000 induced)]-raised experimental IARCs (Oryza sativa L. Jamainadu and Badshabhog) as compared to their respective untreated control.

Fig3: Comparative representation of the status of sensitive redox biomarkers of postimbibitional dehydration stress (PIDS)-raised IARCs, Jamainadu (A) and Badshabhog (B) vis-a-vis their untreated control (Unt. Cont.).

Fig4: Germination and early growth phenotypes of IARCs, Jamainadu and Badshabhog exposed to post-imbibitional dehydration stress [PIDS (PEG-6000 induced)] vis-a-vis their untreated control (Unt. Cont.). Results are mean of three replicates \pm standard error. *Significant from control at 0.05 level (t-test). **Significant from control at 0.01 level (ttest).

Fig 5: QC of total RNA on 1\% Formaldehyde Agarose gel [SBND1: PIDS (-1.619 MPa)raised seedlings of IARC, Jamainadu, SBND2: PIDS (-1.619 MPa)-raised seedlings of IARC, Badshabhog]

Fig 6: Library profile of PIDS (-1.619 MPa)-raised seedlings of IARC, Jamainadu on Agilent DNA HS Chip

Fig 7: Library profile of PIDS (-1.619 MPa)-raised seedlings of IARC, Badshabhog on Agilent DNA HS Chip 
1133

1134

1135

1136

1137

Fig 9: Venn diagram showing the number of genes expressed in both the PIDS-raised seedlings of experimental IARCs [SBND1: PIDS (-1.619 MPa)-raised seedlings of IARC, Jamainadu, SBND2: PIDS (-1.619 MPa)-raised seedlings of IARC, Badshabhog]

Fig 10: Heatmap representing most significant genes expressed in all four samples was plotted using $\log 10$ of normalized read count values (CPM) for SBND1-Vs- SBND2, where shades of blue represents downregulated genes and shades of red represents highly expressed genes. [SBND1: PIDS (-1.619 MPa)-raised seedlings of IARC, Jamainadu, SBND2: PIDS (1.619 MPa)-raised seedlings of IARC, Badshabhog]

Fig 11: MA plot showing differentially expressed transcripts in PIDS (-1.619 MPa)-raised seedlings of IARCs, Jamainadu Vs Badshabhog combination. On X-axis normalized counts for all the samples and on Y-axis $\log 2$ foldchange are plotted. Points colored are with red if the adjusted $\mathrm{p}$ value/q-value is less than 0.05 and black if the adjusted $\mathrm{p}$ value/q-value is greater than 0.05

Fig 12: Volcano plots of the distribution of expressed transcripts in PIDS (-1.619 MPa)raised seedlings of IARCs, Jamainadu Vs Badshabhog combination. Red corresponds to transcripts with adjusted $\mathrm{p}$ value/q-value $<0.05$

Fig 13: GO distribution for SBND1-Vs-SBND2 differentially expressed transcripts [SBND1: PIDS (-1.619 MPa)-raised seedlings of IARC, Jamainadu; SBND2: PIDS (-1.619 MPa)raised seedlings of IARC Badshabhog] 
1152 Fig 14: GO of significant gene number difference under all significant DGE-GO (A) and 1153 GO-WEGO plot showing comparative significant DGE-GO (B) in both the experimental 1154 IARCs (Jamainadu and Badshabhog).

1155 Fig 15: GO of significant gene number difference under uniquely up-regulated 1156 (significant_DGE_GO) (A) and GO-WEGO plot showing comparative nature of uniquely up1157 regulated significant DGE-GO (B) in both the experimental IARCs (Jamainadu and 1158 Badshabhog).

1159 FIG 16: Plant hormone signal transduction KEGG pathway: Purple color entry has been 1160 assigned to at least one gene entry whereas a pink color entry corresponds to an ortholog 1161 table entry, which corresponds to a gene that is a part of a functional unit on the pathway.

1162 FIG 17: Graphical representation of overall bioinformatics workflow. 
Figures

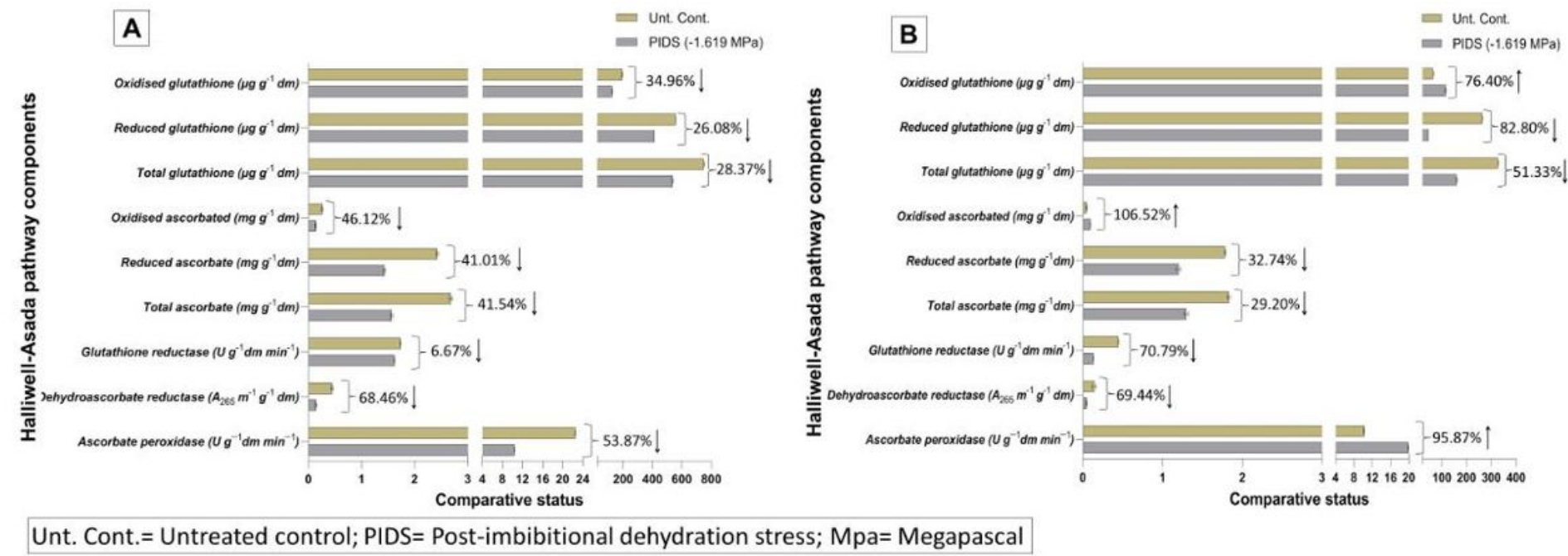

\section{Figure 1}

"See the Supplemental Files section for the complete figure caption". 


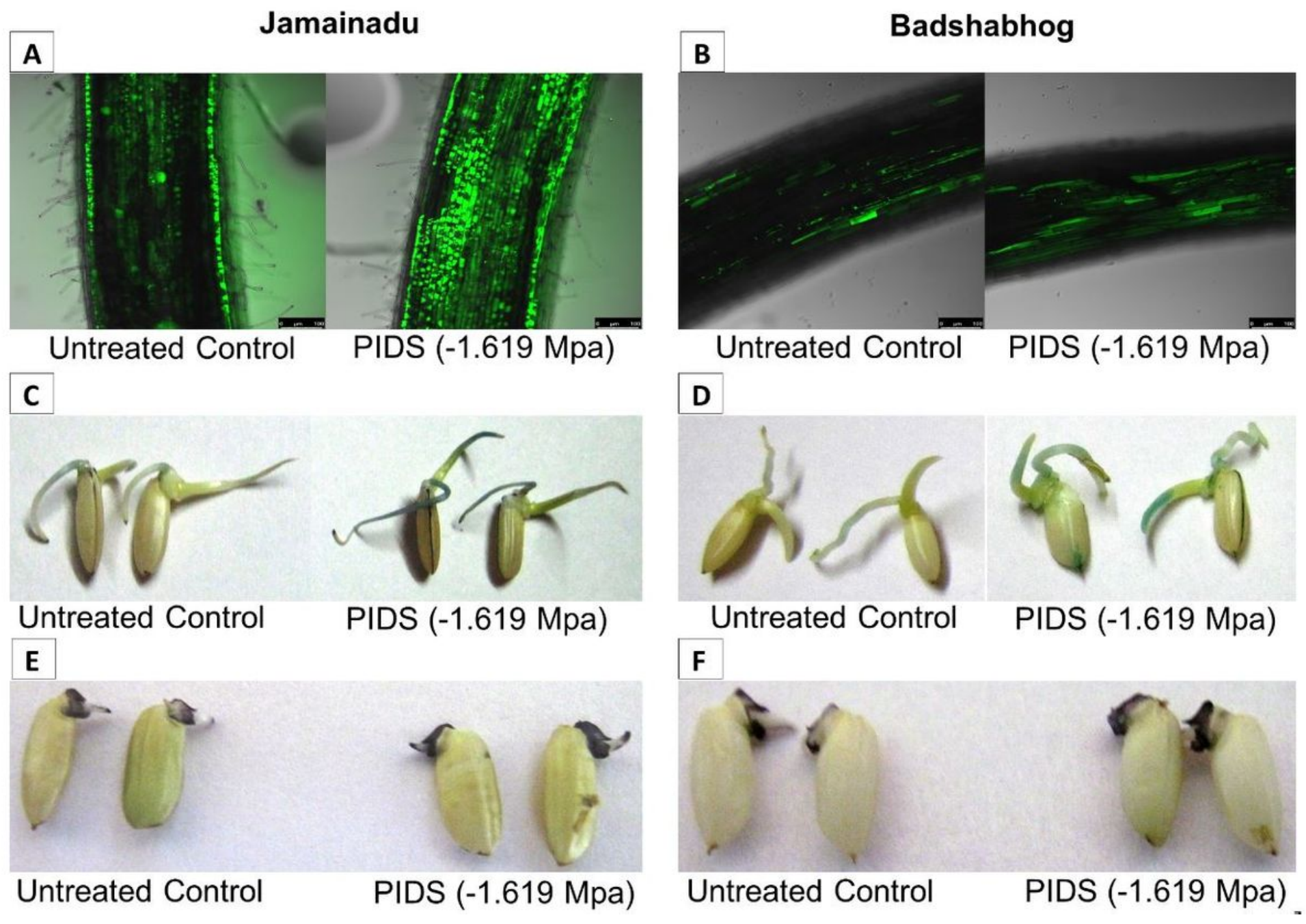

Figure 2

"See the Supplemental Files section for the complete figure caption".
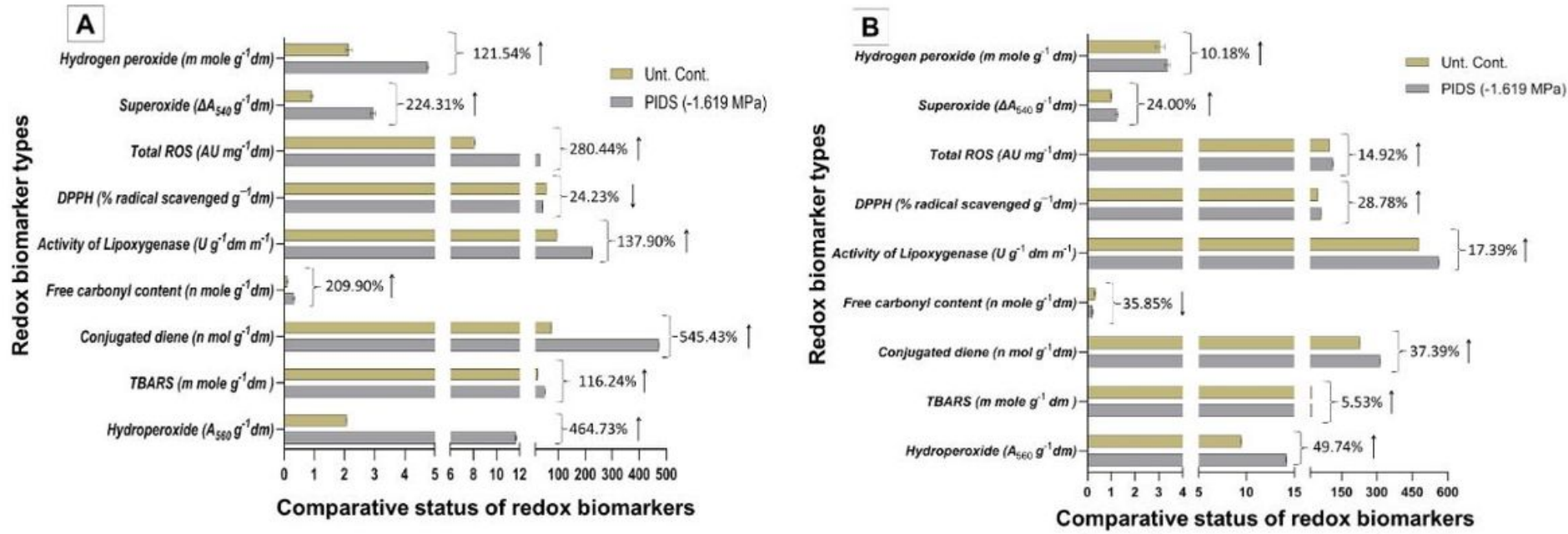

Unt. Cont.= Untreated control; PIDS= Post-imbibitional dehydration stress; $\mathrm{Mpa}=$ Megapascal 
"See the Supplemental Files section for the complete figure caption".

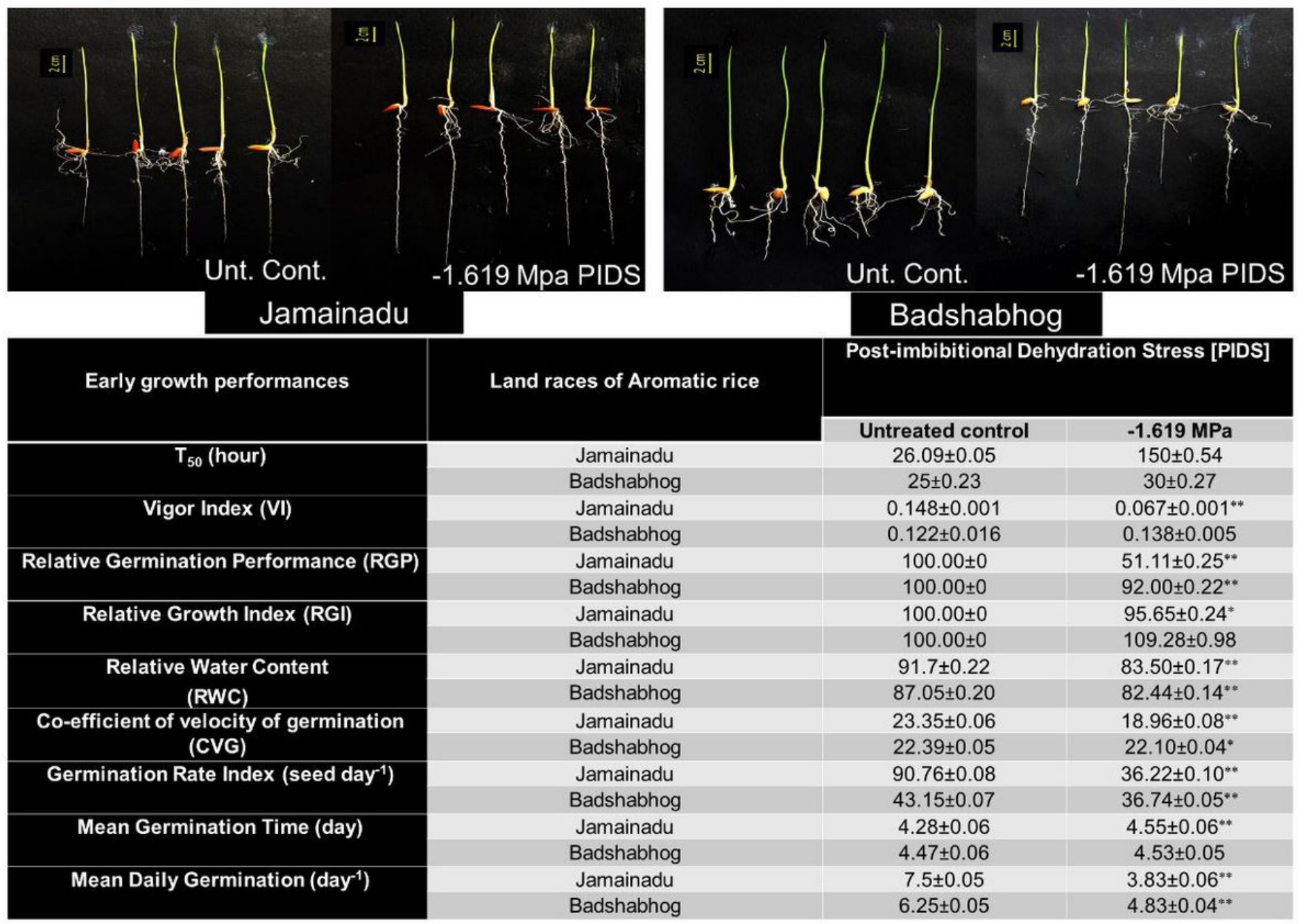

\section{Figure 4}

"See the Supplemental Files section for the complete figure caption". 


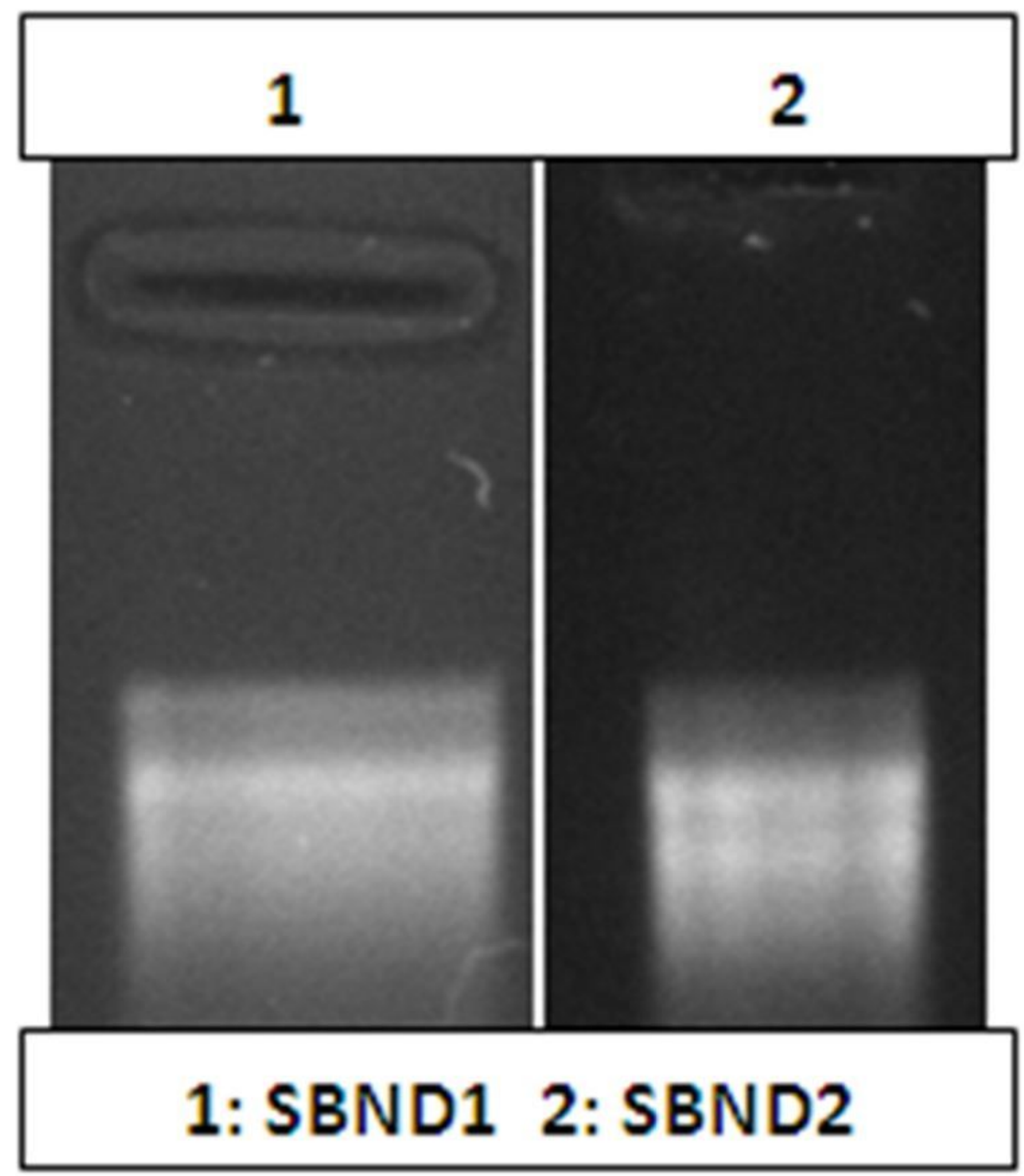

Figure 5

"See the Supplemental Files section for the complete figure caption". 


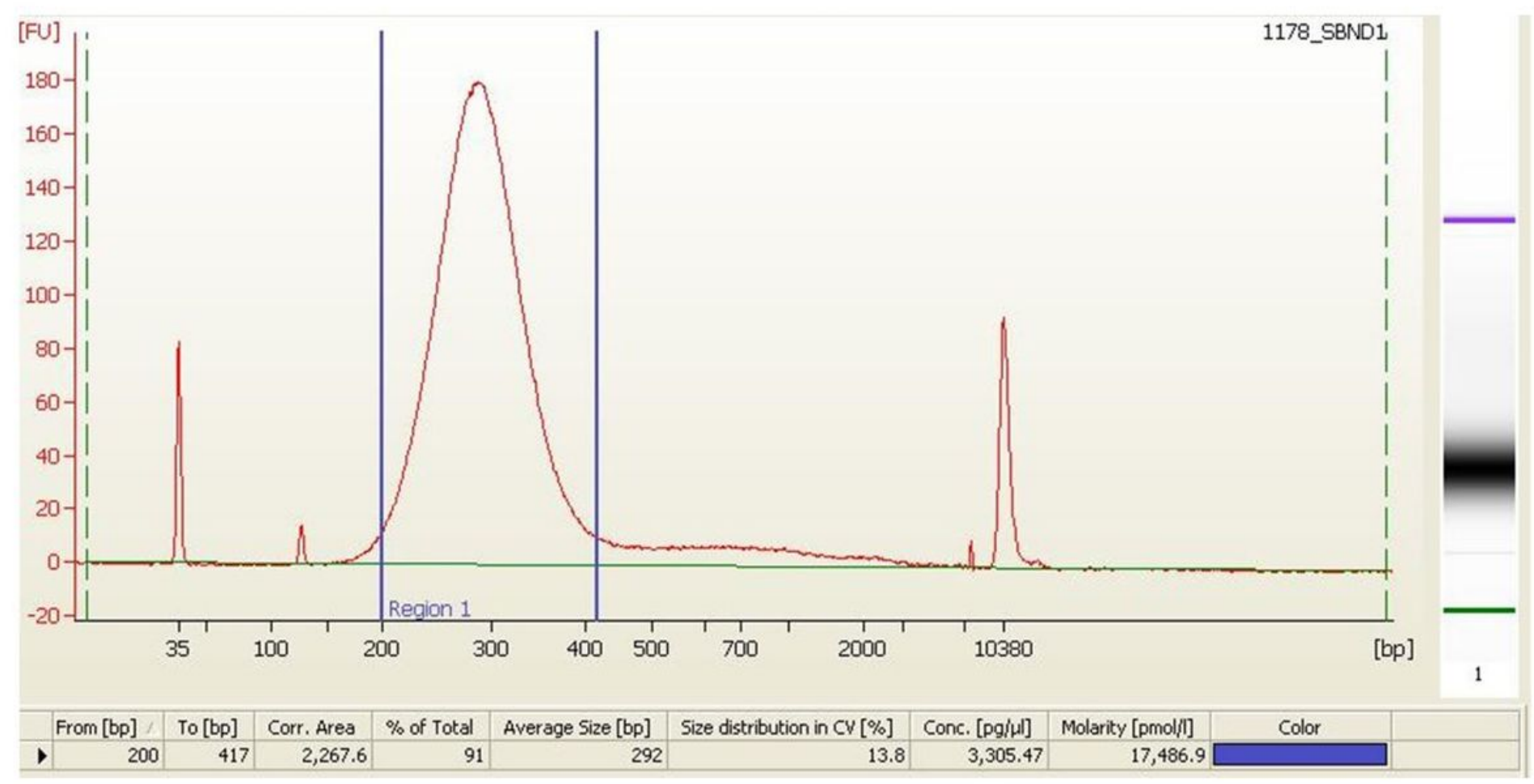

Figure 6

"See the Supplemental Files section for the complete figure caption".

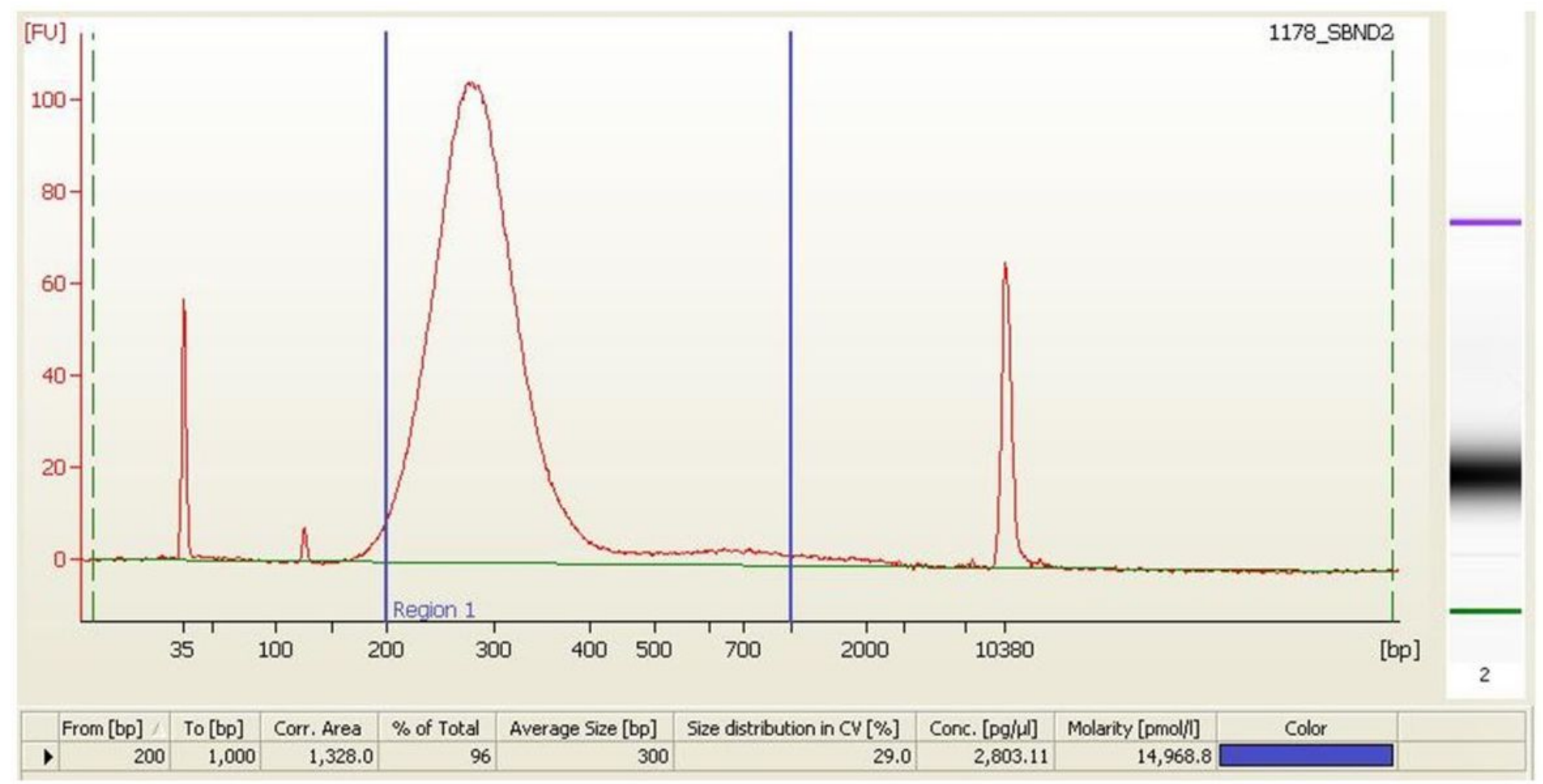

Figure 7 
"See the Supplemental Files section for the complete figure caption".

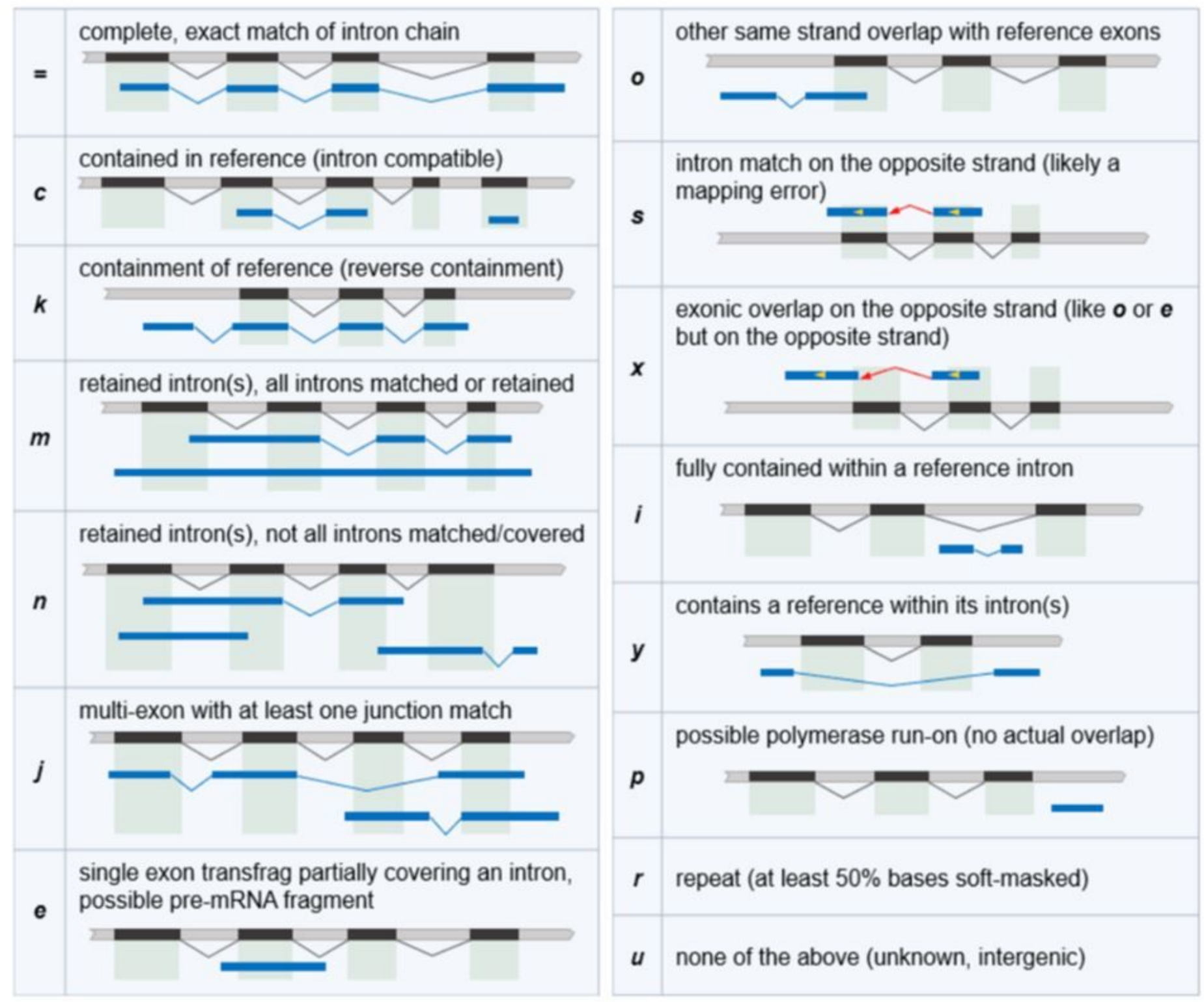

\section{Figure 8}

"See the Supplemental Files section for the complete figure caption". 


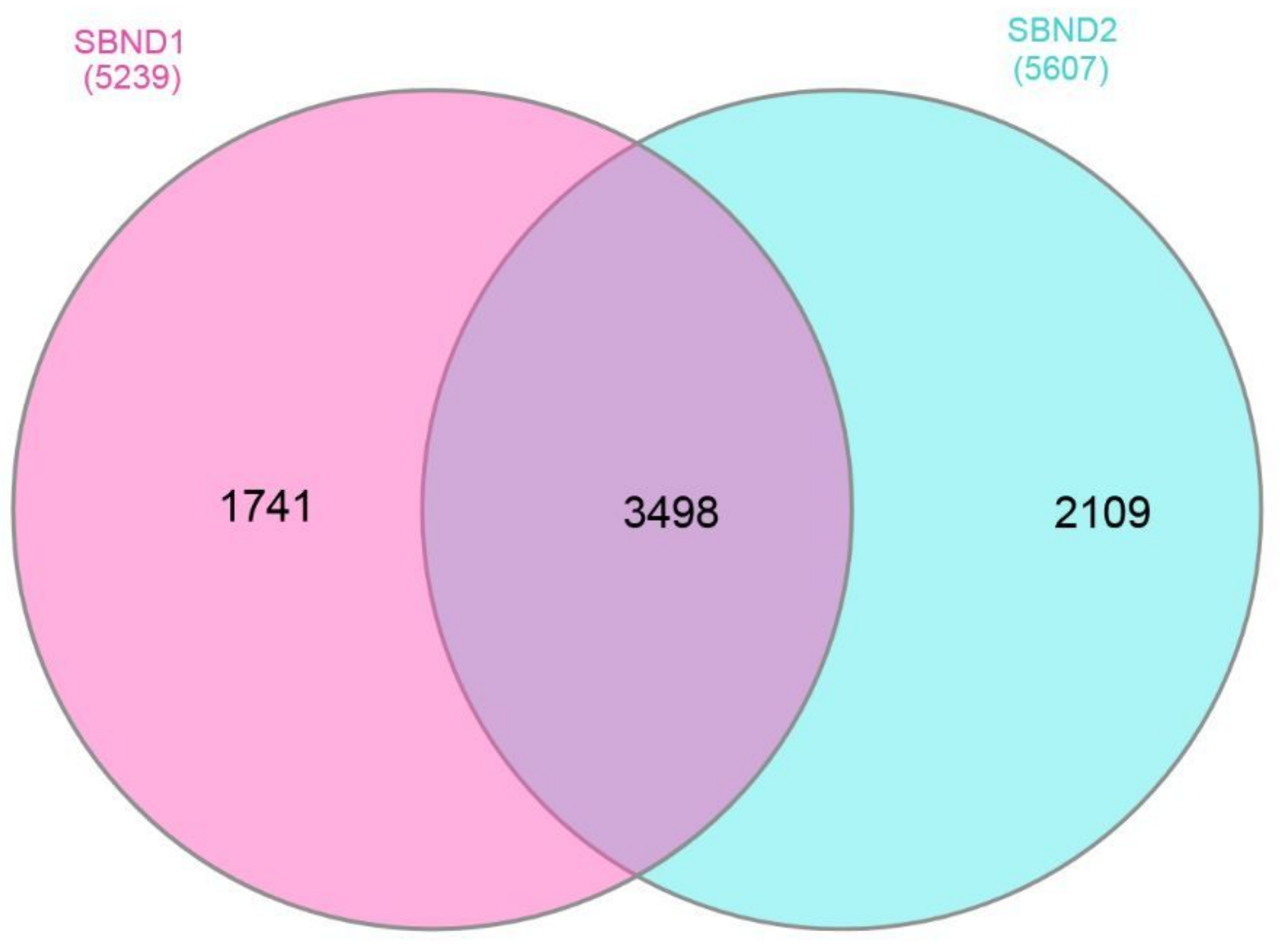

Figure 9

"See the Supplemental Files section for the complete figure caption". 


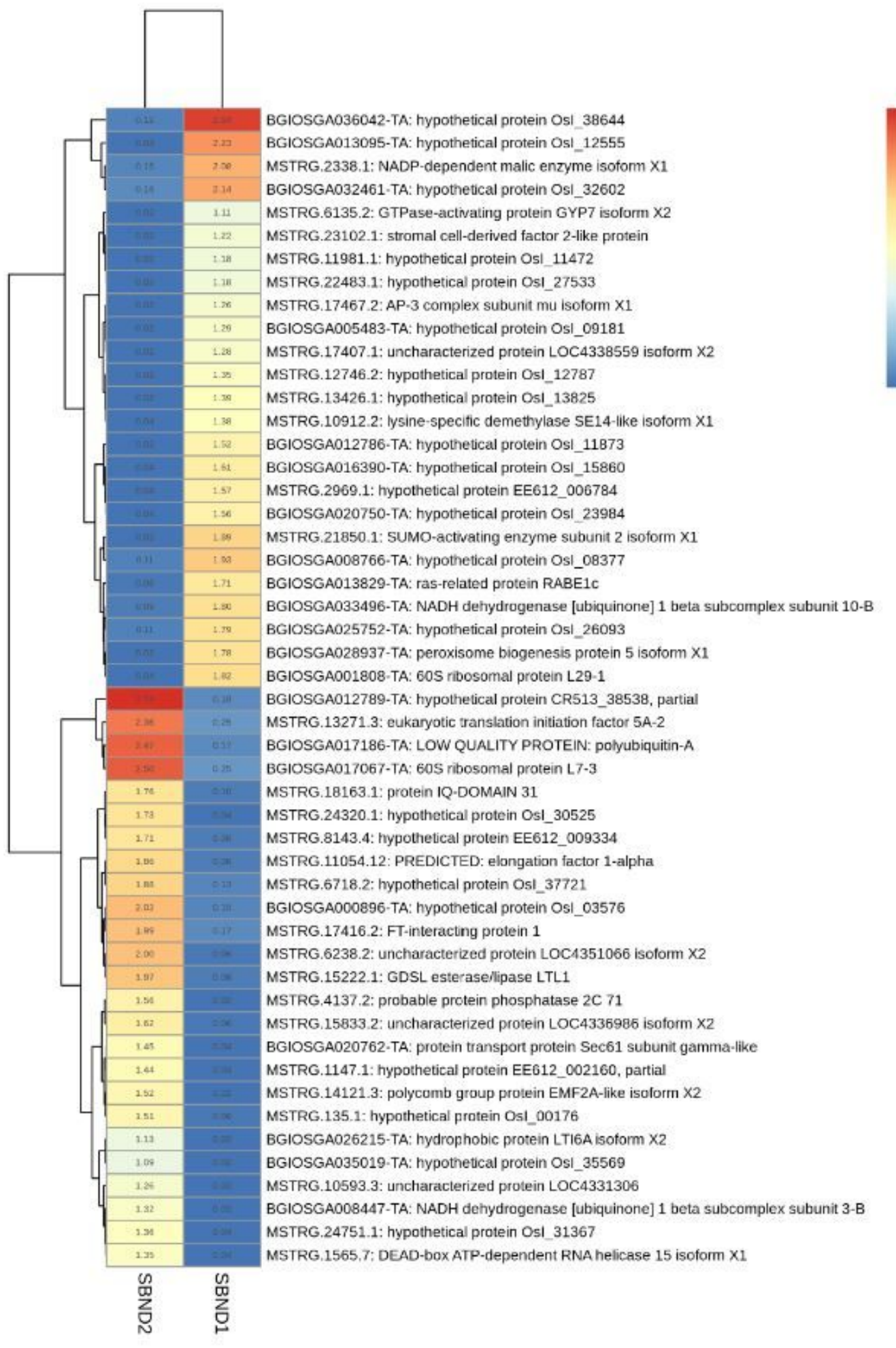

\section{Figure 10}

"See the Supplemental Files section for the complete figure caption". 


\section{MA plot}

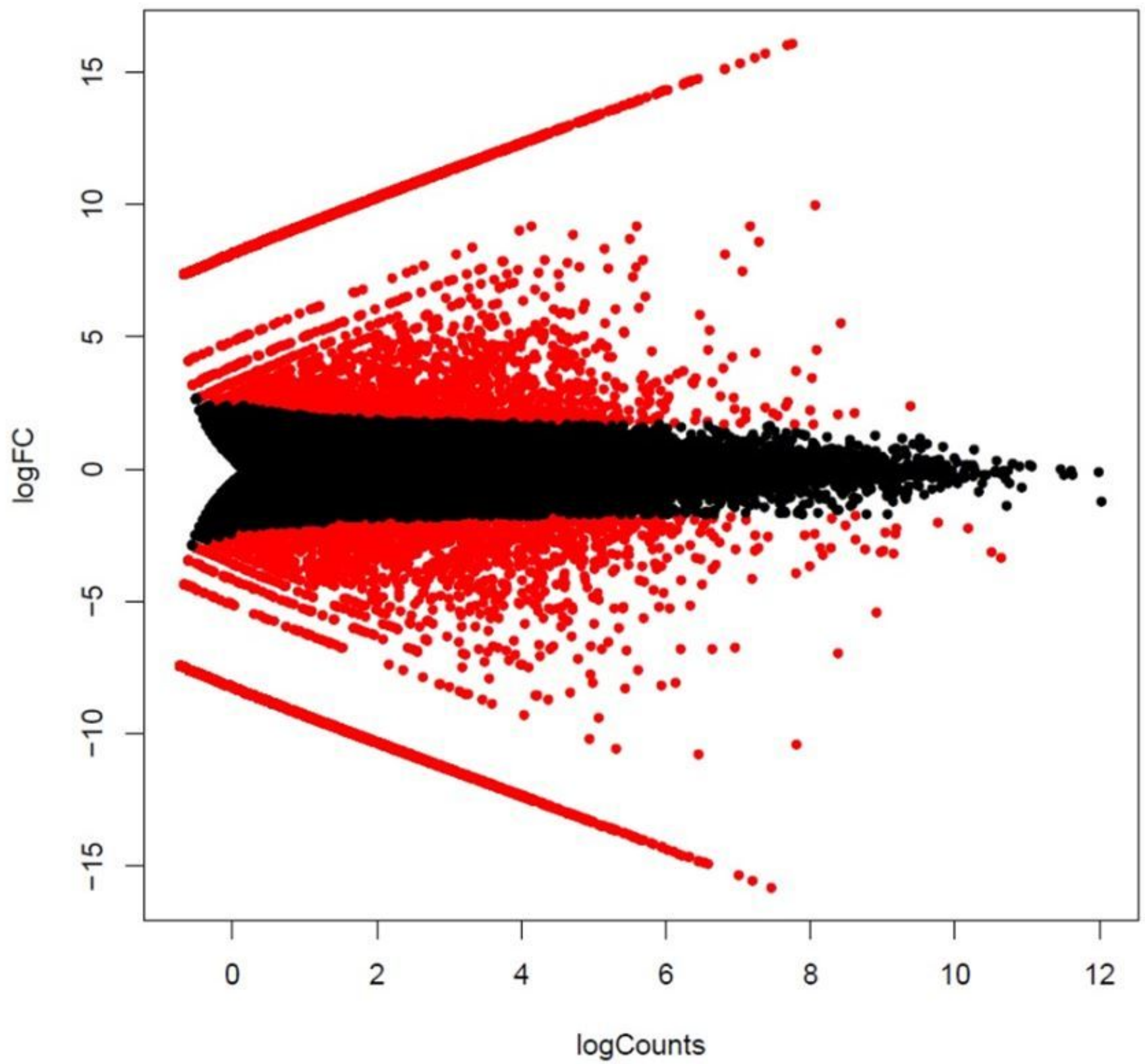

Figure 11

"See the Supplemental Files section for the complete figure caption". 


\section{Volcano plot}

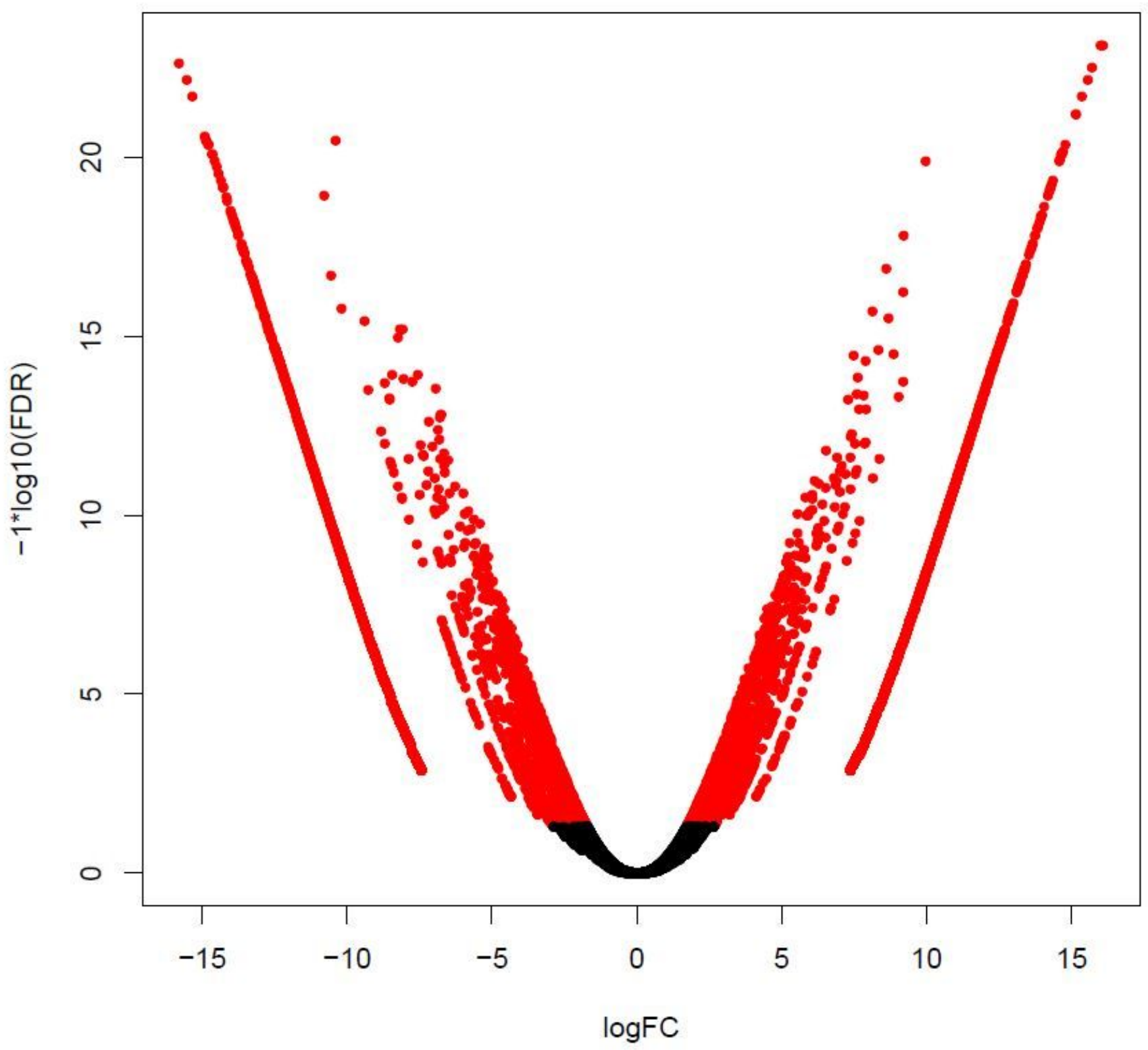

Figure 12

"See the Supplemental Files section for the complete figure caption". 


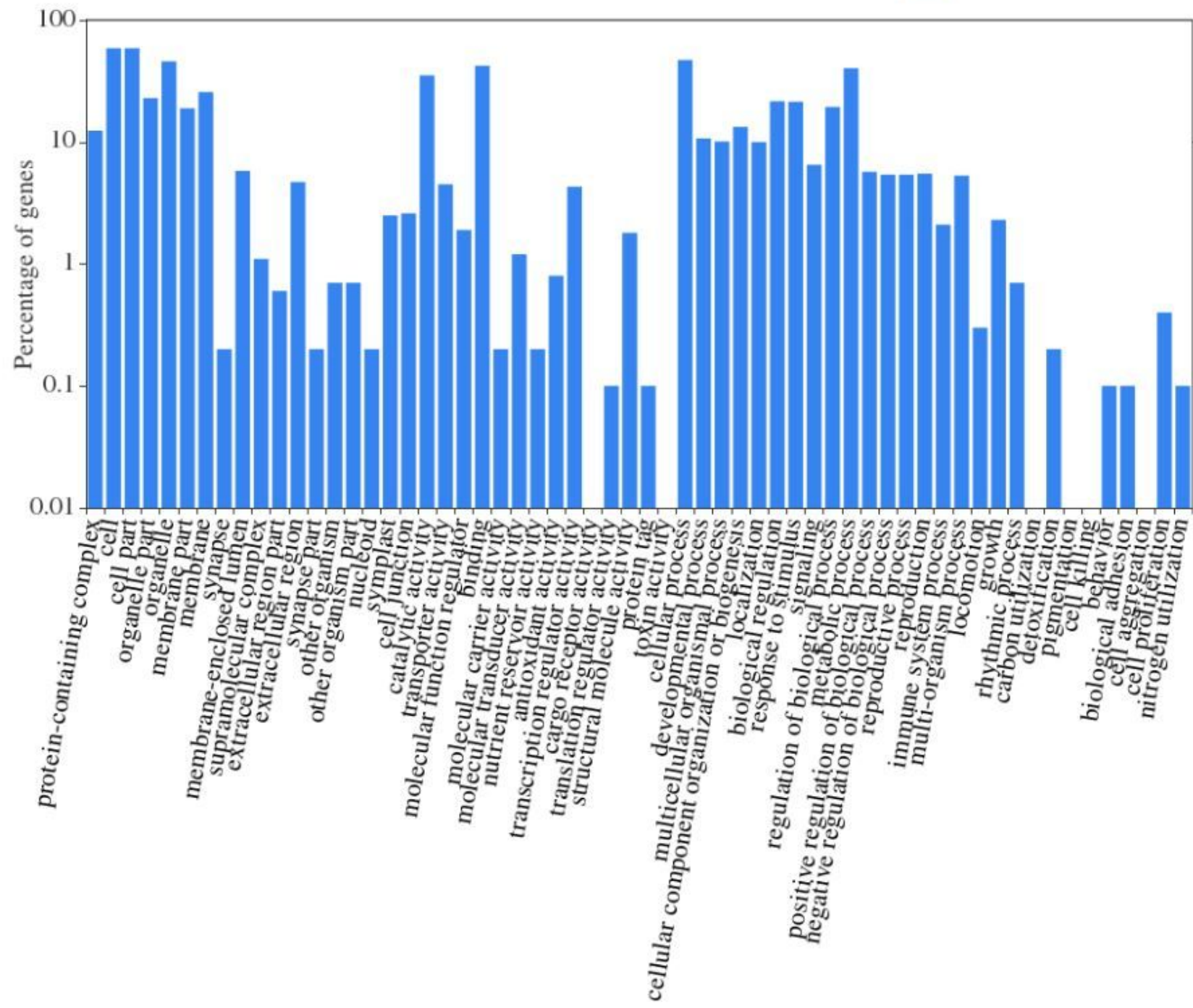

\section{$\checkmark$ L} Molecular Function

Biological Process

Figure 13

"See the Supplemental Files section for the complete figure caption". 

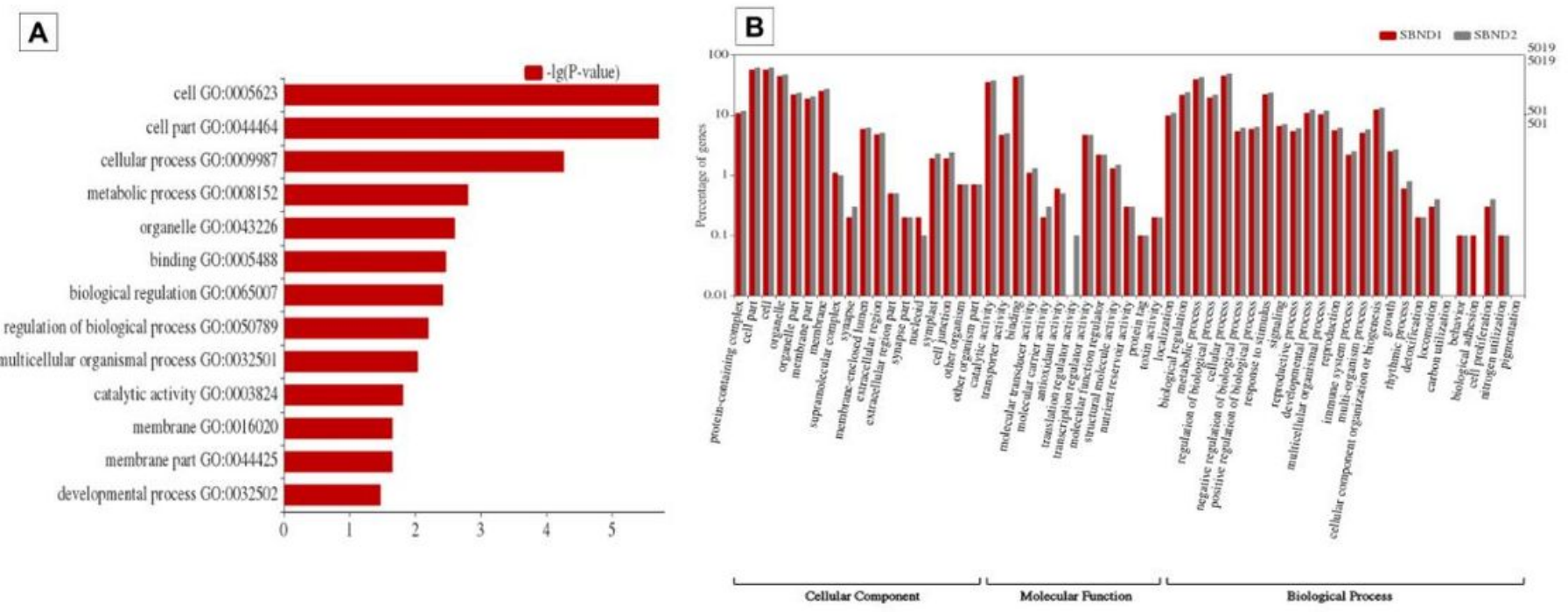

Figure 14

"See the Supplemental Files section for the complete figure caption".
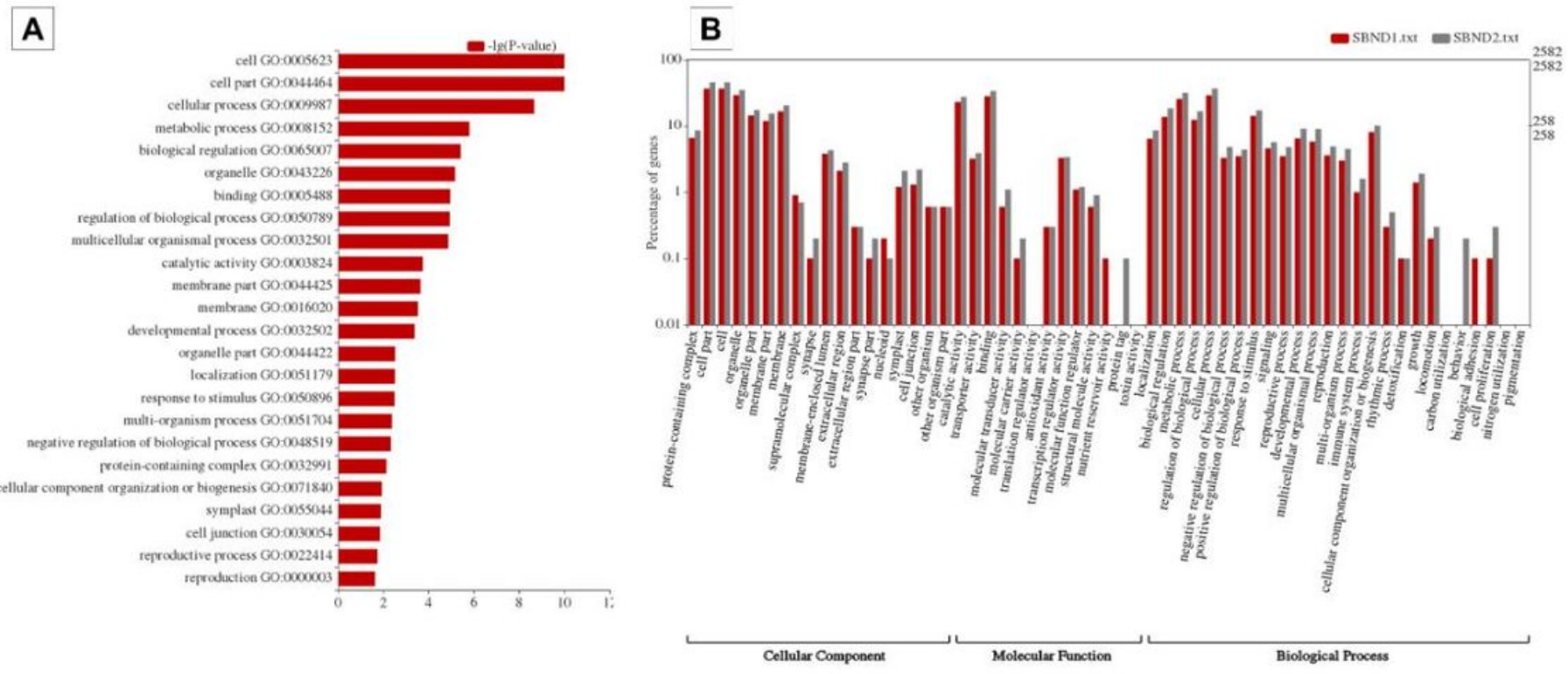

Figure 15

"See the Supplemental Files section for the complete figure caption". 


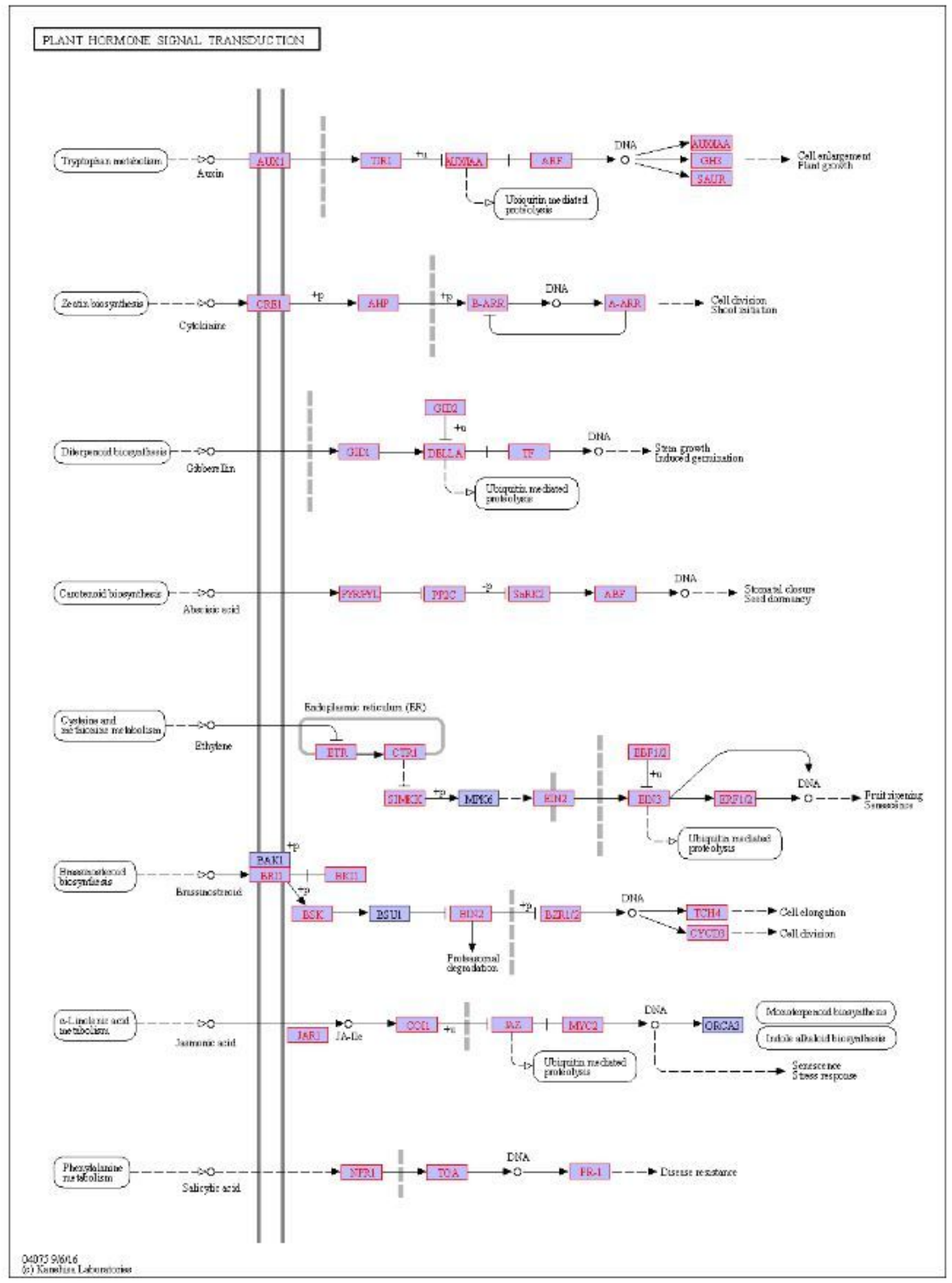

\section{Figure 16}

"See the Supplemental Files section for the complete figure caption". 


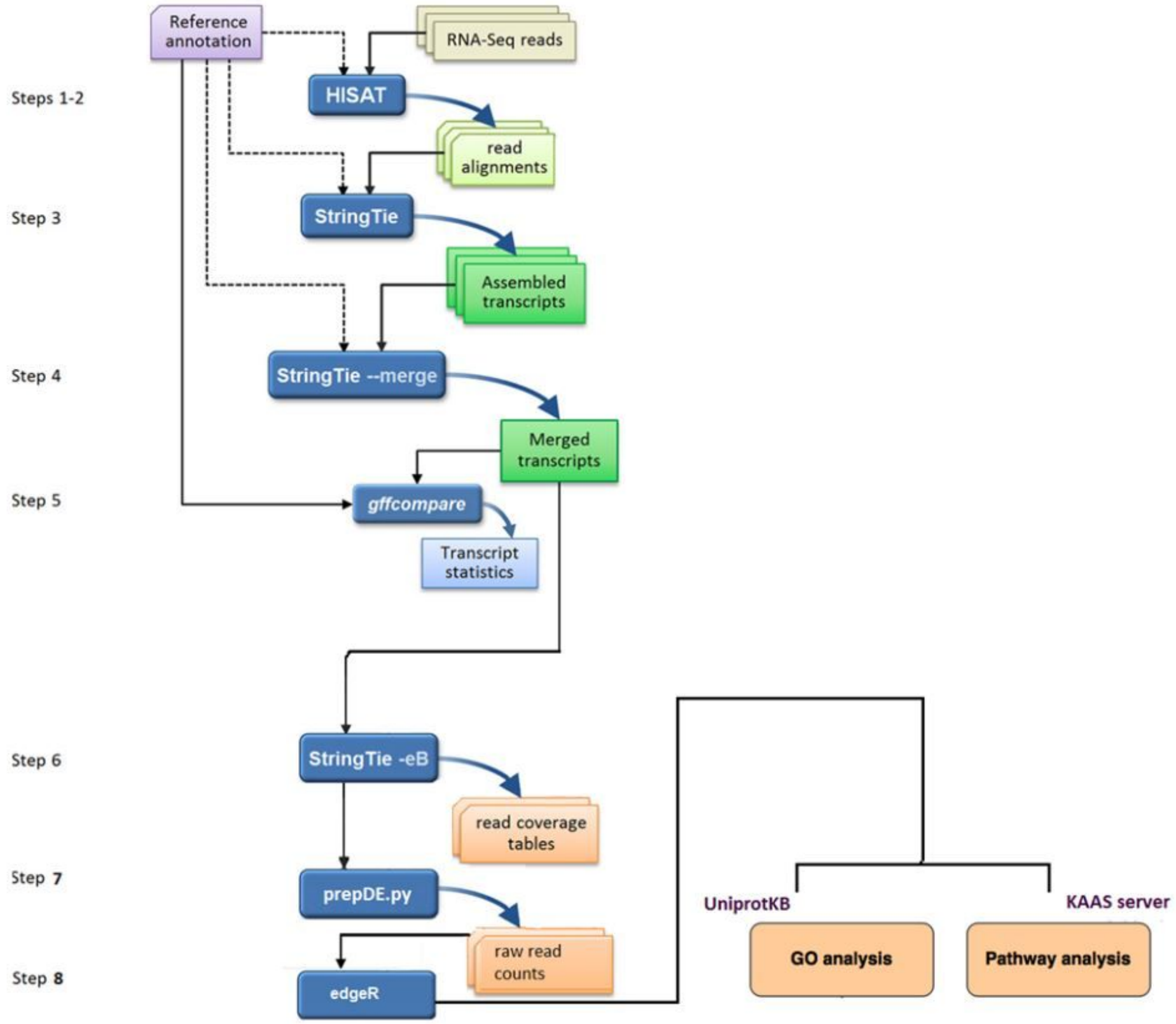

Figure 17

"See the Supplemental Files section for the complete figure caption".

\section{Supplementary Files}

This is a list of supplementary files associated with this preprint. Click to download.

- FigureCaptions.pdf 